\title{
Review
}

\section{Hydrogen sulfide and polysulfides as signaling molecules}

\author{
By Hideo KIMURA*1,
}

(Communicated by Masanori OTsukA, M.J.A.)

\begin{abstract}
Hydrogen sulfide $\left(\mathrm{H}_{2} \mathrm{~S}\right)$ is a familiar toxic gas that smells of rotten eggs. After the identification of endogenous $\mathrm{H}_{2} \mathrm{~S}$ in the mammalian brain two decades ago, studies of this molecule uncovered physiological roles in processes such as neuromodulation, vascular tone regulation, cytoprotection against oxidative stress, angiogenesis, anti-inflammation, and oxygen sensing. Enzymes that produce $\mathrm{H}_{2} \mathrm{~S}$, such as cystathionine $\beta$-synthase, cystathionine $\gamma$-lyase, and 3 mercaptopyruvate sulfurtransferase have been studied intensively and well characterized. Polysulfides, which have a higher number of inner sulfur atoms than that in $\mathrm{H}_{2} \mathrm{~S}$, were recently identified as potential signaling molecules that can activate ion channels, transcription factors, and tumor suppressors with greater potency than that of $\mathrm{H}_{2} \mathrm{~S}$. This article focuses on our contribution to the discovery of these molecules and their metabolic pathways and mechanisms of action.
\end{abstract}

Keywords: hydrogen sulfide, polysulfides, neuromodulator, vascular relaxant, cytoprotectant, TRPA1

\section{Background: From toxic gas to signaling molecule}

In 1988, nitric oxide (NO) was discovered as a gaseous signaling molecule that regulates vascular tone and neuronal activity in the brain. ${ }^{1)-4)}$ It was

\footnotetext{
*1 Department of Molecular Pharmacology, National Institute of Neuroscience, NCNP, Tokyo, Japan.

$\dagger$ Correspondence should be addressed: H. Kimura, Department of Molecular Pharmacology, National Institute of Neuroscience, NCNP, 4-1-1 Ogawahigashi, Kodaira, Tokyo 187-8502, Japan (e-mail: kimura@ncnp.go.jp).

Abbreviations: CAT: cysteine aminotransferase; CBS: cystathionine $\beta$-synthase; CO: carbon monoxide; CSE: cystathionine $\gamma$-lyase; DAO: D-amino acid oxidase; DHLA: dihydrolipoic acid; DS: Down syndrome; DTT: dithiothreitol; $\mathrm{EC}_{50}$ : halfmaximal effective concentration; eNOS: nitric oxide synthase 3 , ER: endoplasmic reticulum; GAPDH: glyceraldehyde 3-phosphate dehydrogenase; GCL: glutamate cysteine ligase; GSH: glutathione; GSSH: glutathione persulfide; $\mathrm{H}_{2} \mathrm{~S}$ : hydrogen sulfide; $\mathrm{H}_{2} \mathrm{~S}_{\mathrm{n}}$ polysulfide; HPLC: high performance liquid chromatography; HSIP-1: hydrogen sulfide imaging prove-1; $\mathrm{K}_{\mathrm{ATP}}$ : ATP-sensitive $\mathrm{K}^{+}$; Keap1: Kelch ECH-associating protein 1; LTP: long-term potentiation; 3MP: 3-mercaptopyruvate; 3MST: 3-mercaptopyruvate sulfurtransferase; NADPH: nicotinamide adenine dinucleotide phosphate; NaHS: sodium hydrosulfide; $\mathrm{Na}_{2} \mathrm{~S}_{3}$ : sodium trisulfide; $\mathrm{Na}_{2} \mathrm{~S}_{4}$ : sodium tetrasulfide; NF- $\kappa \mathrm{B}$ : nuclear factor- $\kappa \mathrm{B}$; NMDA: N-methyl D,L-aspartate; NO: nitric oxide; Nrf2: nuclear factor erythroid 2-related factor 2; PLP: pyridoxal 5'-phosphate; PTP: protein tyrosine phosphatase; SAM: S-adenosyl methionine; SNP: sodium nitroprusside; SQR: sulfide-quinone oxidoreductase; TRP: transient receptor potential; TRPA1: TRP ankyrin 1.
}

later found to regulate synaptic activity for memory formation and learning. ${ }^{5)}$ In 1993, carbon monoxide $(\mathrm{CO})$ was discovered as a second gaseous signaling molecule that facilitated memory formation. ${ }^{6)-8)}$ Given these findings, we searched for a novel gaseous molecule that regulates neuronal activity and is involved in memory formation. Since the first description of hydrogen sulfide $\left(\mathrm{H}_{2} \mathrm{~S}\right)$ as a toxic gas by Ramazzini in $1713,{ }^{9)}$ many toxicity studies of this molecule have been undertaken. Memory loss is common in survivors of $\mathrm{H}_{2} \mathrm{~S}$ poisoning, and victims have coordination and psychiatric disturbances. ${ }^{10)}$ In animal models, acute intoxication induced by high concentrations of $\mathrm{H}_{2} \mathrm{~S}$ changes neurotransmitter levels at synapses in the brain and activates $\mathrm{Ca}^{2+}$ channels as well as $\mathrm{Ca}^{2+}$-activated $\mathrm{K}^{+}$channels in dorsal raphe serotonergic cells. ${ }^{11), 12)}$ These observations suggest that $\mathrm{H}_{2} \mathrm{~S}$ has a significant effect on neuronal activity.

In 1989, Warenycia et al. ${ }^{13), 14)}$ discovered endogenous sulfide in mammalian brains while studying how much exogenously applied $\mathrm{H}_{2} \mathrm{~S}$ remains in the brain. After the application of $\mathrm{H}_{2} \mathrm{~S}$ via inhalation or intraperitoneal injection of sodium hydrosulfide (NaHS), a salt of $\mathrm{H}_{2} \mathrm{~S}$, they observed that the amount of $\mathrm{H}_{2} \mathrm{~S}$ in the brain increased in a dose-dependent manner. Surprisingly, $\mathrm{H}_{2} \mathrm{~S}$ was detected even without the application of $\mathrm{H}_{2} \mathrm{~S}$, which indicated the presence 

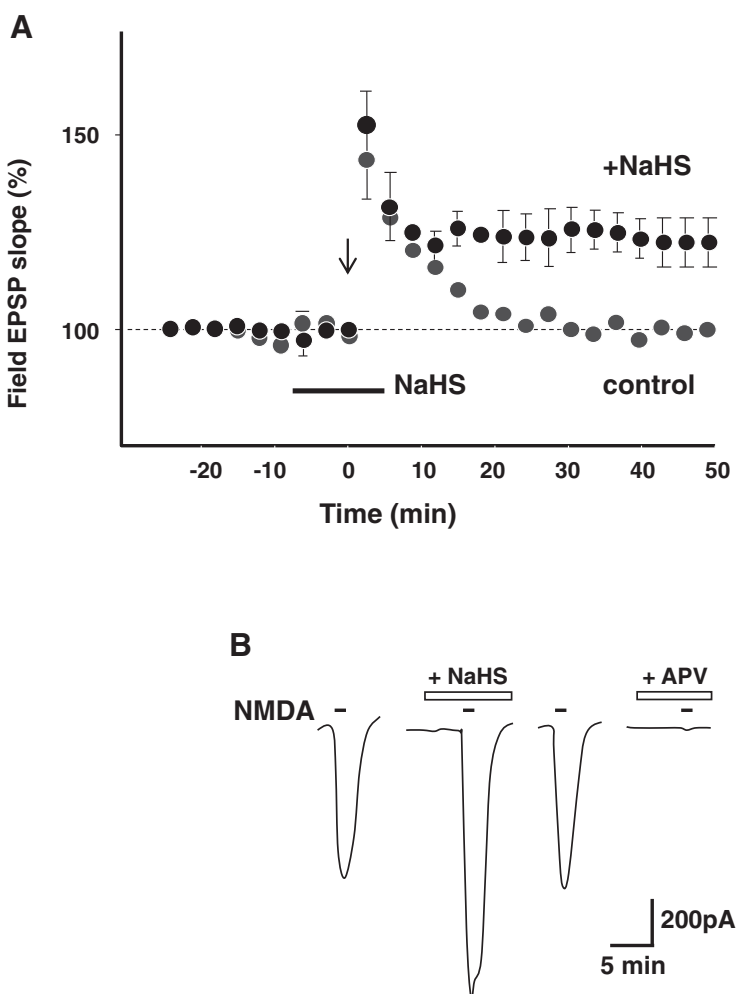

D

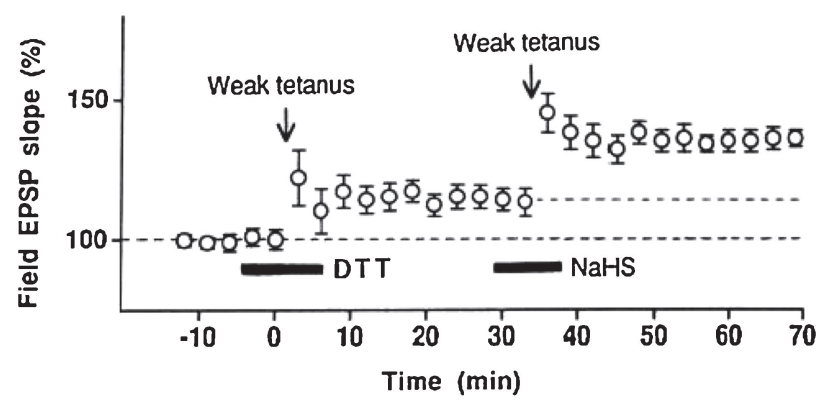

C
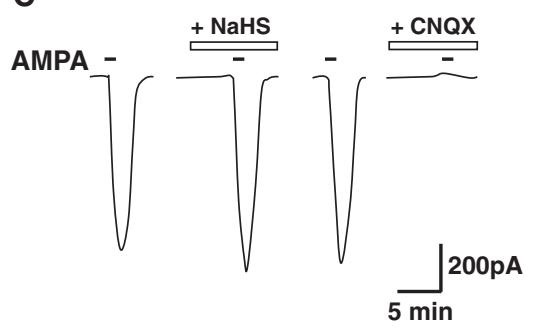

Fig. 1. $\mathrm{H}_{2} \mathrm{~S}$ facilitates the induction of hippocampal long-term potentiation (LTP) by enhancing the activity of NMDA receptors. A. A weak-tetanic stimulation, which alone does not induce LTP, induces LTP in the presence of $\mathrm{H}_{2} \mathrm{~S}$. B and $\mathrm{C}$. $\mathrm{H}_{2} \mathrm{~S}$ enhances the activity of NMDA receptors but not that of AMPA receptors, another type of ionotropic glutamate receptors. D. A lower concentration of NaHS, a sodium salt of $\mathrm{H}_{2} \mathrm{~S}$, further facilitated the induction of LTP even after DTT treatment. (Figures in 19 were modified).

of endogenous $\mathrm{H}_{2} \mathrm{~S}$. This discovery urged us to study the physiological roles of this molecule in the nervous system.

$\mathrm{H}_{2} \mathrm{~S}$-producing enzymes were studied extensively between the $1950 \mathrm{~s}$ and $1970 \mathrm{~s}$; however, $\mathrm{H}_{2} \mathrm{~S}$ was thought to be merely a by-product of metabolic pathways or a marker for the activities of specific enzymes. ${ }^{15)-18)}$ In 1996, we demonstrated that $\mathrm{H}_{2} \mathrm{~S}$ facilitates the induction of hippocampal long-term potentiation (LTP) by enhancing the activity of $\mathrm{N}$-methyl D-aspartate (NMDA) receptors, and that cystathionine $\beta$-synthase (CBS) produces $\mathrm{H}_{2} \mathrm{~S}$ in the brain $^{19)}$ (Figs. 1 and 2). Using these observations, we proposed a possible role for $\mathrm{H}_{2} \mathrm{~S}$ as a neuromodulator in the brain. Solomon Snyder of the Johns Hopkins University commented in an interview in Science News that our evidence supported the categorization of $\mathrm{H}_{2} \mathrm{~S}$ as a neurotransmitter. ${ }^{20)}$ In 2009, Snyder et $a l^{21)}$ demonstrated a mode of action for $\mathrm{H}_{2} \mathrm{~S}$, suggesting that it adds sulfur to cysteine residues of target proteins - a process called sulfhydration which induces conformational changes in the proteins and alters their activity. In the same year, we showed that this sulfur addition reaction generates bound sulfane sulfur, which we proposed as the intracellular storage molecule of $\mathrm{H}_{2} \mathrm{~S} .{ }^{22)}$

$\mathrm{H}_{2} \mathrm{~S}$ also apparently has a role in the vasculature. We found that cystathionine $\gamma$-lyase (CSE) is an $\mathrm{H}_{2} \mathrm{~S}$-producing enzyme in smooth muscle and that $\mathrm{H}_{2} \mathrm{~S}$ is a smooth muscle relaxant ${ }^{23)}$ (Fig. 3). The idea to investigate the possibility of these roles originated in the results of studies of NO, which has roles in both the nervous and the vascular systems. After the discovery of vascular system roles for NO, Garthwaite et al. ${ }^{4)}$ demonstrated that NO is also released through the NMDA receptors of brain neurons in a $\mathrm{Ca}^{2+}$-dependent manner. Bredt and Snyder ${ }^{24)}$ subsequently identified NO synthase in the brain.

$\mathrm{H}_{2} \mathrm{~S}$ relaxes the thoracic aorta, portal vein, and ileum. ${ }^{23)}$ However, the relaxation effect on the thoracic aorta is significantly weaker than that on the portal vein and the ileum. We found the effect of $\mathrm{H}_{2} \mathrm{~S}$ is greatly augmented by the presence of $\mathrm{NO}$, 
A

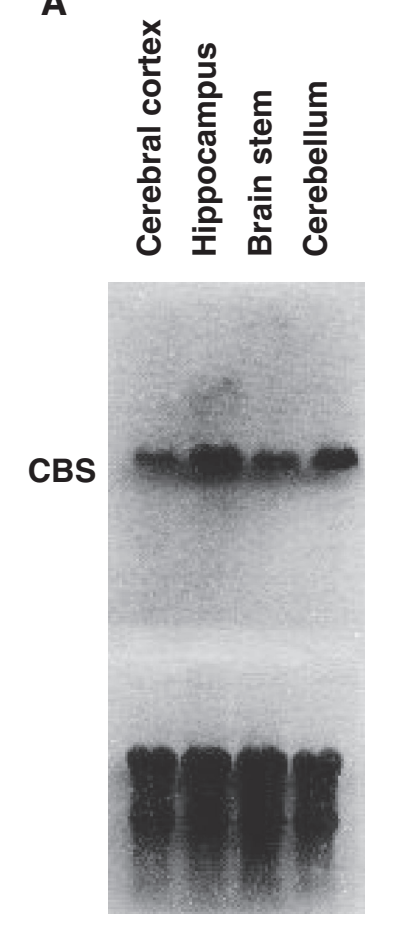

B

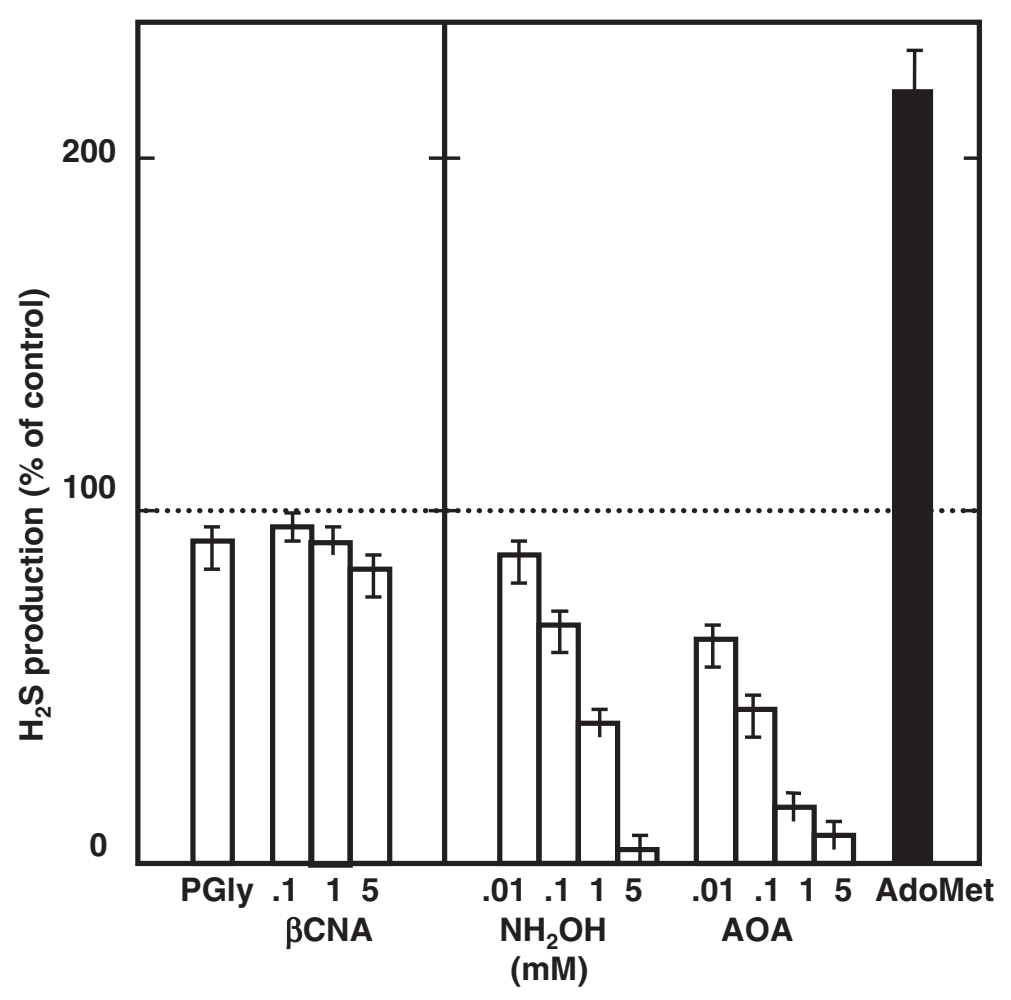

Fig. 2. The expression of CBS in the brain and the production of $\mathrm{H}_{2} \mathrm{~S}$. A. CBS is expressed in the brain. B. The production of $\mathrm{H}_{2} \mathrm{~S}$ is suppressed by hydroxylamine $\left(\mathrm{NH}_{2} \mathrm{OH}\right)$ and aminooxyacetate (AOA), inhibitors of CBS, but not by propargylglycine (PGly), an inhibitor of CSE. S-adenosyl methionine (AdoMet) enhances the production of $\mathrm{H}_{2} \mathrm{~S}$ (Figures in 19 were modified).

which suggests a synergy between these two molecules $^{23)}$ (see Fig. 3). This synergistic effect was confirmed in the twitch responses of the ileum by Teagues et al. ${ }^{25}$ ) With respect to the mechanism of $\mathrm{H}_{2} \mathrm{~S}$ effects on the vasculature, Zhao et al. ${ }^{26)}$ identified ATP-sensitive $\mathrm{K}^{+}$channels as $\mathrm{H}_{2} \mathrm{~S}$ targets for relaxation and hyperpolarization in vascular smooth muscle. Mustafa et al. ${ }^{27)}$ later identified endothelial $\mathrm{Ca}^{2+}$-sensitive intermediate conductance and small conductance $\mathrm{K}^{+}$channels as target molecules as well. Further highlighting of the various roles of $\mathrm{H}_{2} \mathrm{~S}$ continues in the following discussion of the basic properties of this molecule and its enzymatic production.

\section{Basic properties of $\mathrm{H}_{2} \mathrm{~S}$}

$\mathrm{NO}, \mathrm{CO}$, and $\mathrm{O}_{2}$ barely dissolve in water; $100 \mathrm{~mL}$ of water dissolves $5.6 \mathrm{mg}, 2.76 \mathrm{mg}$ at $20^{\circ} \mathrm{C}$, and $3.93 \mathrm{mg}$ at $25^{\circ} \mathrm{C}$, respectively. By contrast, $413 \mathrm{mg} \mathrm{H}_{2} \mathrm{~S}$ dissolves in $100 \mathrm{~mL}$ of water at $20^{\circ} \mathrm{C}$. In solution, $\mathrm{H}_{2} \mathrm{~S}$ dissociates into $\mathrm{H}^{+}$and $\mathrm{HS}^{-}$and further to $\mathrm{S}^{2-}$ under alkaline conditions. Under physiological conditions (i.e., $37^{\circ} \mathrm{C}$ and $\mathrm{pH} 7.4$ ), approximately $20 \%$ of $\mathrm{H}_{2} \mathrm{~S}$ exists as a gas and the remainder as $\mathrm{HS}^{-}$with a trace amount of $\mathrm{S}^{2-}$.

$$
\begin{aligned}
& \mathrm{H}_{2} \mathrm{~S} \rightarrow \mathrm{H}^{+}+\mathrm{HS}^{-}\left(\mathrm{pK}_{1} 7.04\right) \\
& \mathrm{HS}^{-} \rightarrow \mathrm{H}^{+}+\mathrm{S}^{2-}\left(\mathrm{pK}_{2}\right. \text { 11.96) }
\end{aligned}
$$

$\mathrm{pK}$ values were obtained from Reiffenstein et al. ${ }^{10)}$ Note also that Meyer et al. ${ }^{28)}$ reported a $\mathrm{pK}_{2}$ of 13.78 .

Because it is difficult to determine which form of $\mathrm{H}_{2} \mathrm{~S}\left(\mathrm{H}_{2} \mathrm{~S}, \mathrm{HS}^{-}\right.$, or $\left.\mathrm{S}^{2-}\right)$ is active, the term "hydrogen sulfide" is used to include all forms. ${ }^{19)}$ The term "gasotransmitter" has often been used for hydrogen sulfide, which can mislead readers into believing that $\mathrm{H}_{2} \mathrm{~S}$ gas is the only active form.

Given that intracellular $\mathrm{pH}$ is approximately 7.0 in the cytosol, 6.0-6.7 in the Golgi apparatus, and 4.7 in lysosomes, the ratio of $\mathrm{H}_{2} \mathrm{~S} / \mathrm{HS}^{-}$likely varies among subcellular compartments. ${ }^{29)}$ Although the precise ratio of $\mathrm{H}_{2} \mathrm{~S} / \mathrm{HS}^{-}$in each organelle has not been measured, it is likely higher (i.e., a greater 

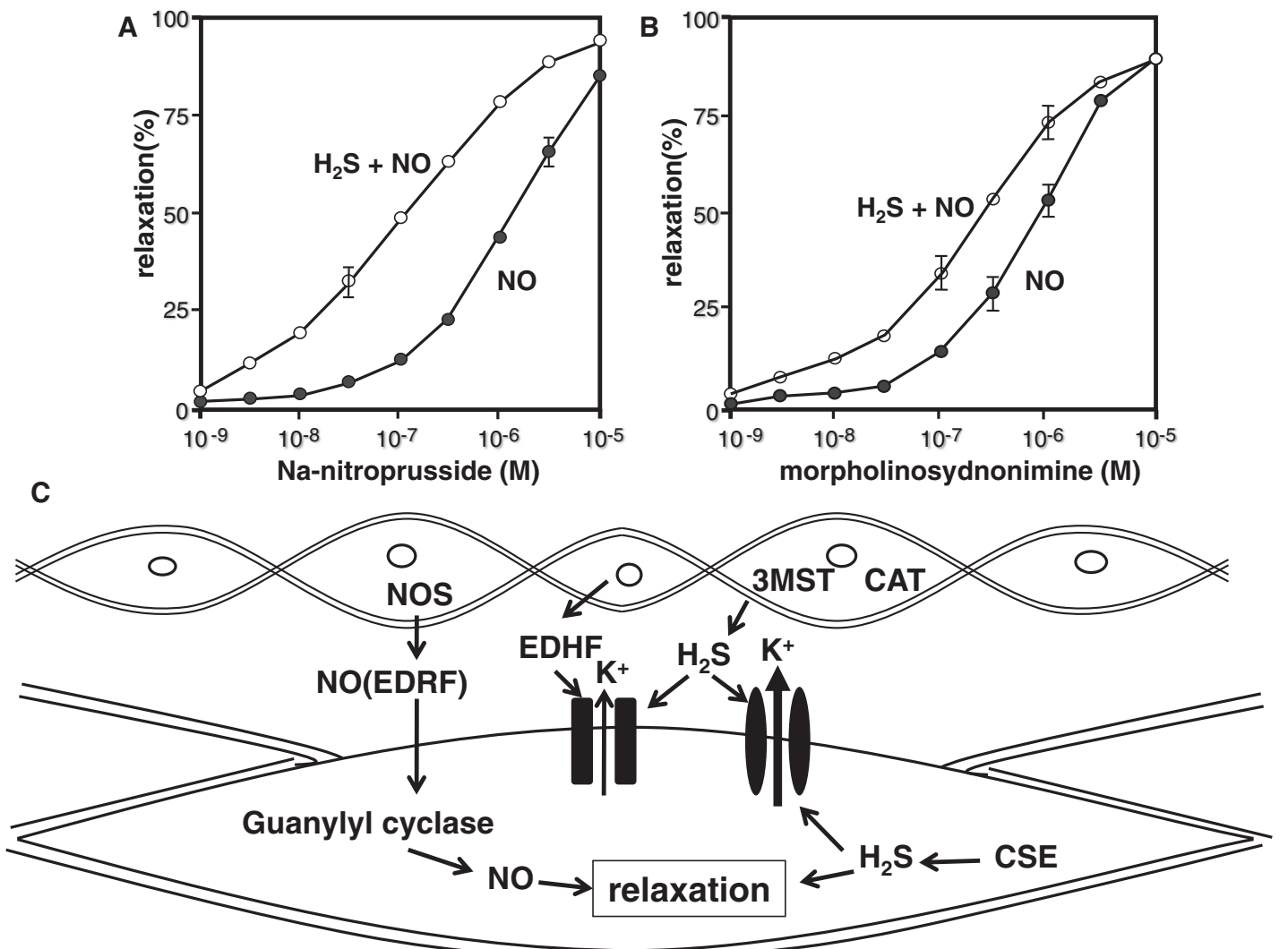

Fig. 3. A synergistic effect of $\mathrm{H}_{2} \mathrm{~S}$ with $\mathrm{NO}$ on vascular smooth muscle relaxation. The vascular relaxation effect of sodium nitroprusside (A) and morpholinosydnonimine (B) is greatly enhanced in the presence of $\mathrm{H}_{2} \mathrm{~S}$ (Figures in 23 were modified). C. $\mathrm{H}_{2} \mathrm{~S}$, which is produced by 3MST together with CAT in endothelium and CSE in smooth muscle, relaxes smooth muscle and hyperpolarizes the membrane potential by activating potassium channels.

amount of undissociated $\mathrm{H}_{2} \mathrm{~S}$ ) in subcellular compartments in which the $\mathrm{pH}$ is more acidic.

$\mathrm{H}_{2} \mathrm{~S}$ has a molecular structure similar to that of $\mathrm{H}_{2} \mathrm{O}$; the distance between $\mathrm{H}$ and $\mathrm{S}$ in the former is $0.134 \mathrm{~nm}$, whereas that between $\mathrm{H}$ and $\mathrm{O}$ in the latter is $0.0957 \mathrm{~nm}$. The angle of $\mathrm{H}-\mathrm{S}-\mathrm{H}$ is $92^{\circ}$, whereas that of $\mathrm{H}-\mathrm{O}-\mathrm{H}$ is $104.52^{\circ}$. Despite these structural similarities, $\mathrm{H}_{2} \mathrm{~S}$ does not pass through aquaporins or water channels. ${ }^{30)} \mathrm{H}_{2} \mathrm{~S}$ also dissolves well in lipids and readily passes through lipid bilayers, even those containing cholesterol and sphingomyelin, both of which decrease membrane diffusion. The lower limit of lipid bilayer permeability to $\mathrm{H}_{2} \mathrm{~S}$ is $0.5 \mathrm{~cm} / \mathrm{s}$, which is greater than that to $\mathrm{NH}_{3}(0.016 \mathrm{~cm} / \mathrm{s})$ but lower than that to $\left.\mathrm{CO}_{2}(3.2 \mathrm{~cm} / \mathrm{s}){ }^{30}\right)$ Another diffusion model proposed by Cuevasanta et al. ${ }^{31)}$ estimates the permeability of $\mathrm{H}_{2} \mathrm{~S}$ at $0.85 \mathrm{~cm} / \mathrm{s}$. Considering that intracellular $\mathrm{pH}$ is lower than extracellular $\mathrm{pH}, \mathrm{H}_{2} \mathrm{~S}$ passes more quantitatively through plasma membranes in the intracellular to extracellular direction.
Theoretical calculations by Mathai et al. ${ }^{30)}$ indicate that transport of $\mathrm{HS}^{-}$by anion channels is unlikely to occur under physiological conditions. However, the anion-exchange protein AE1 was recently found to transport $\mathrm{HS}^{-}$in exchange for $\mathrm{Cl}^{-}$in erythrocytes. ${ }^{32)} \mathrm{H}_{2} \mathrm{~S}$ and $\mathrm{HS}^{-}$rapidly enter erythrocytes, which may act as a sink for $\mathrm{H}_{2} \mathrm{~S}$ and regulate its local extracellular concentrations (Fig. 4).

An $\mathrm{HS}^{-}$channel has also been identified in bacteria. $^{33)}$ Because the extracellular environment of bacteria is acidic ( $\mathrm{pH}$ 6.0) and intracellular $\mathrm{pH}$ is 7.4, $\mathrm{HS}^{-}$concentrations are much greater inside the cells than outside, where $\mathrm{H}_{2} \mathrm{~S}$ gas is dominant. Therefore, $\mathrm{H}_{2} \mathrm{~S}$ passes through the bacterial membrane from the extracellular into the intracellular environment. However, in contrast to $\mathrm{H}_{2} \mathrm{~S}$ production in mammals, $\mathrm{H}_{2} \mathrm{~S}$ produced in bacteria dissociates to $\mathrm{HS}^{-}$, which can pass through $\mathrm{HS}^{-}$channels to the extracellular environment and be released as $\mathrm{H}_{2} \mathrm{~S}$ gas (see Fig. 4). 


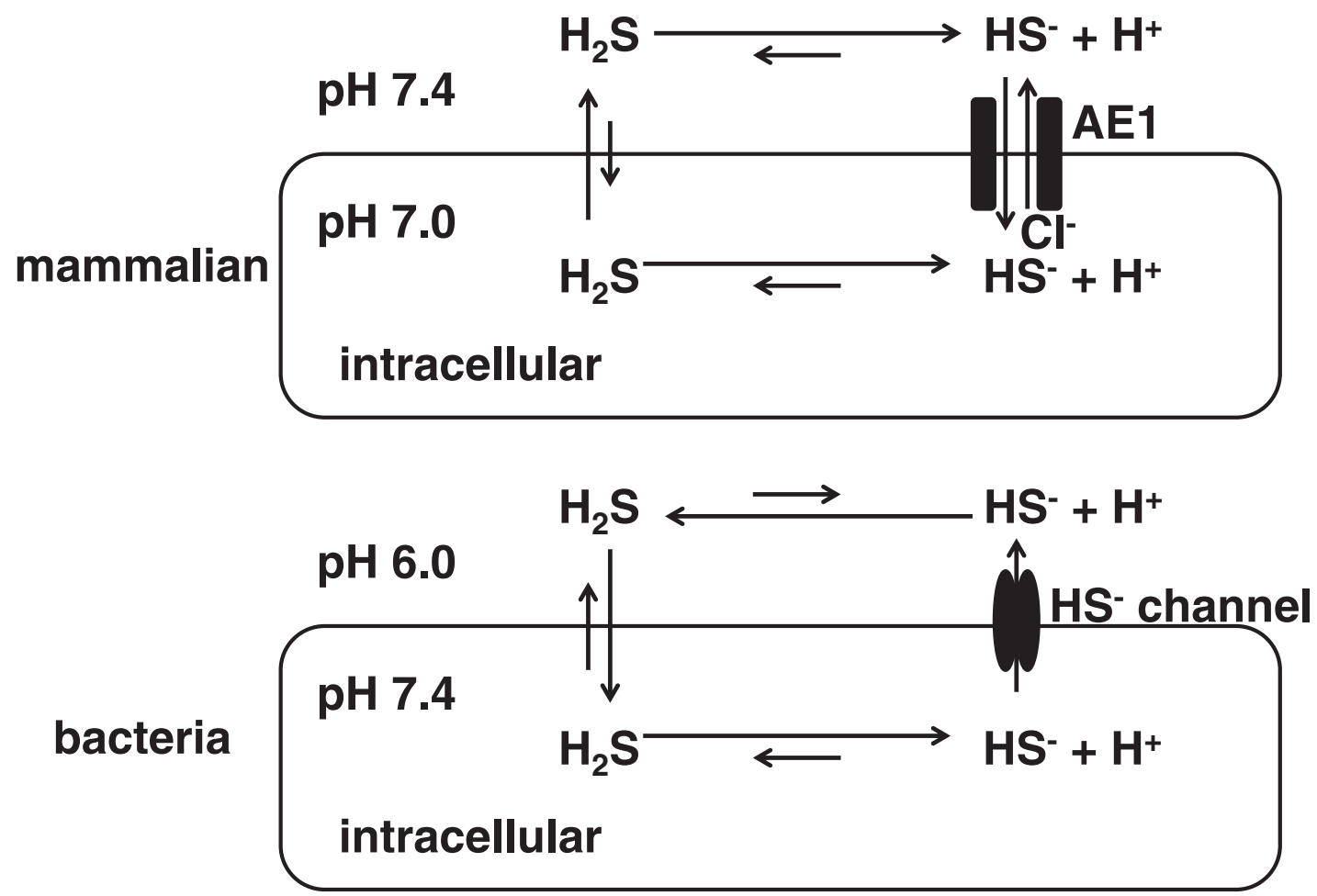

Fig. 4. $\mathrm{H}_{2} \mathrm{~S}$ passes through the membrane and $\mathrm{HS}^{-}$through $\mathrm{HS}^{-}$channels. $\mathrm{H}_{2} \mathrm{~S}$ dissociates to $\mathrm{HS}^{-}$and $\mathrm{H}^{+}$with a trace amount of $\mathrm{S}^{2-}$ under physiological conditions. At $\mathrm{pH} 7.4$ and $37^{\circ} \mathrm{C}$, approximately $20 \% \mathrm{H}_{2} \mathrm{~S}$ exists as a gas, and remaining $80 \%$ as $\mathrm{HS}^{-}$. In mammalian cells, $\mathrm{H}_{2} \mathrm{~S}$ passes through the plasma membrane and then dissociates under the extracellular environment where $\mathrm{pH}$ is slightly higher than inside the cell. The anion exchange protein AE1 transports $\mathrm{HS}^{-}$in exchange for $\mathrm{Cl}^{-}$. In bacteria, $\mathrm{HS}^{-}$is released through $\mathrm{HS}^{-}$channels to the extracellular environment, while $\mathrm{H}_{2} \mathrm{~S}$ enters into cells through the plasma membrane similar to that seen for mammalian cells.

\section{Endogenous $\mathrm{H}_{2} \mathrm{~S}$}

In addition to being present as free $\mathrm{H}_{2} \mathrm{~S}, \mathrm{H}_{2} \mathrm{~S}$ is produced by enzymes and released from cellular stores. ${ }^{22)}$ Two stored forms of $\mathrm{H}_{2} \mathrm{~S}$ have been identified: acid-labile sulfur and bound sulfane sulfur. Acid-labile sulfur is mainly found in an iron-sulfur complex attached to enzymes belonging to the respiratory chain. This complex releases $\mathrm{H}_{2} \mathrm{~S}$ under acidic conditions. Conversely, bound sulfane sulfur, which exists as the sulfurated cysteine residues of proteins, releases $\mathrm{H}_{2} \mathrm{~S}$ under reducing conditions (Fig. 5).

3.1. Acid-labile sulfur. The concentrations of endogenous free $\mathrm{H}_{2} \mathrm{~S}$ reported in initial studies ${ }^{13), 14)}$ were later found to be overestimations due to inappropriate methods of measurement. ${ }^{22), 34), 35)}$ Specifically, the measurements were made under strong acidic conditions in which acid-labile sulfur releases $\mathrm{H}_{2} \mathrm{~S}$ in much greater amounts than those observed naturally. Nevertheless, we wanted to determine whether acid-labile sulfur functions as an $\mathrm{H}_{2} \mathrm{~S}$ store in cells. The $\mathrm{pH}$ at which $\mathrm{H}_{2} \mathrm{~S}$ is released from acidlabile sulfur is $5.4 .^{22)}$ Given that the enzymes containing the iron-sulfur complex — which contains acid-labile sulfur, - are mainly localized to the mitochondria, in which the $\mathrm{pH}$ is approximately 8 and acid-labile sulfur is abundant, ${ }^{36)} \mathrm{H}_{2} \mathrm{~S}$ may not be released from acid-labile sulfur under physiological conditions (see Fig. 5). Although iron-sulfur complexes also release $\mathrm{H}_{2} \mathrm{~S}$ when they are detached from enzymes by detergents and protein denaturants, this may not occur under physiological conditions. ${ }^{22}$ )

3.2. Bound sulfane sulfur. Bound sulfane sulfur is incorporated into proteins as persulfide or polysulfide, which release $\mathrm{H}_{2} \mathrm{~S}$ under reducing conditions (see Fig. 5). We observed the absorption of $\mathrm{H}_{2} \mathrm{~S}$ in tissues and found that the rate of absorption depends on tissue type. Absorbed $\mathrm{H}_{2} \mathrm{~S}$ can be recovered with a reducing substance such as dithiothreitol (DTT). ${ }^{22), 36)} \mathrm{H}_{2} \mathrm{~S}$ must be oxidized to bind to proteins as a persulfide or polysulfide. ${ }^{37)}$ Because 


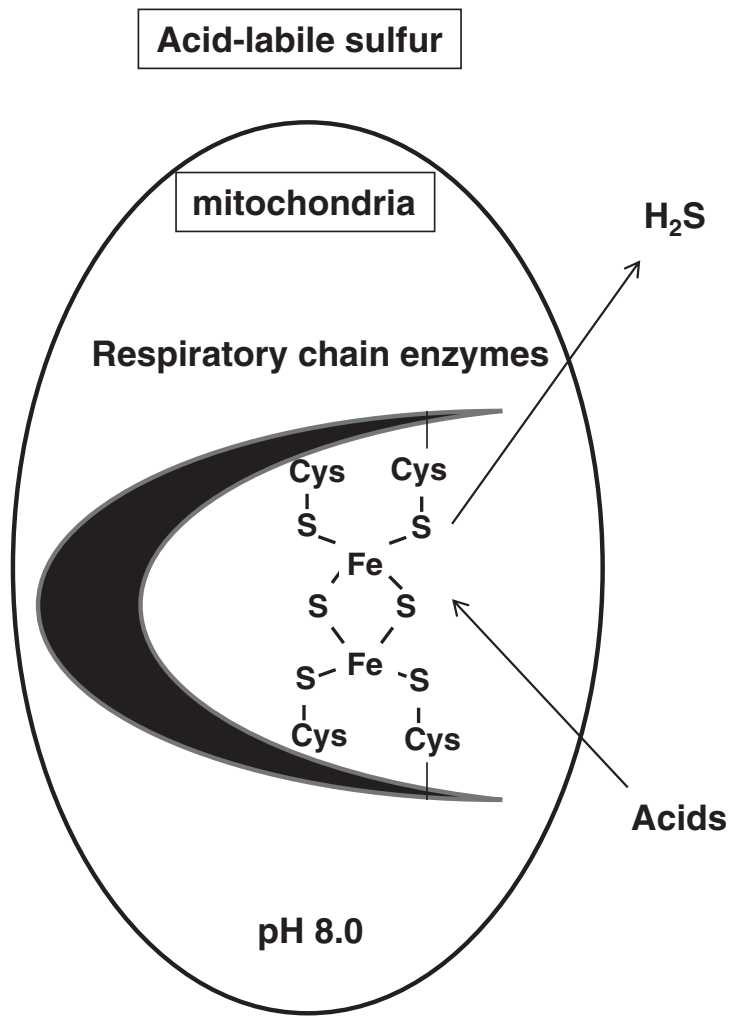

\section{Bound sulfane sulfur}

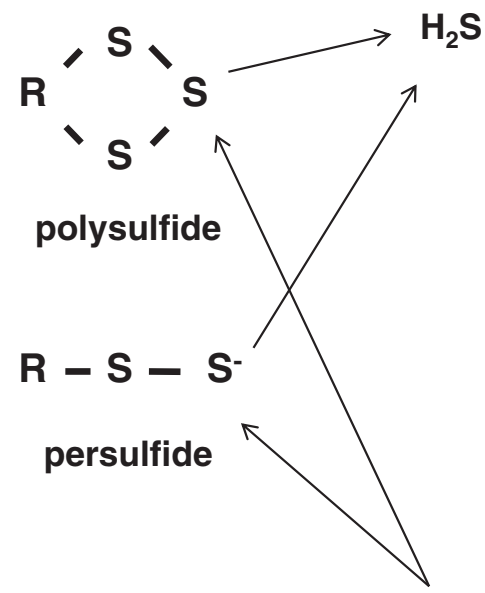

Reducing agents

Fig. 5. Two forms of intracellular sulfur that can release $\mathrm{H}_{2} \mathrm{~S}$. The iron-sulfur cluster, which localizes to the active center of enzymes in the respiratory chain and releases $\mathrm{H}_{2} \mathrm{~S}$ under acidic conditions, forms the major acid-labile sulfur in cells. Bound sulfane sulfur, which consists of polysulfide and persulfide bound to proteins, releases $\mathrm{H}_{2} \mathrm{~S}$ under reducing conditions and may form the intracellular storage for $\mathrm{H}_{2} \mathrm{~S}$.

exogenously applied $\mathrm{H}_{2} \mathrm{~S}$ is absorbed and stored in proteins, we predicted that endogenous $\mathrm{H}_{2} \mathrm{~S}$ produced by enzymes might also be incorporated into proteins. To this end, we found that cells expressing 3mercaptopyruvate sulfurtransferase (3MST) and cysteine aminotransferase (CAT) contain increased levels of bound sulfane sulfur. ${ }^{38)}$ By contrast, cells expressing a defective mutant 3MST, in which activecenter cysteine 247 is replaced with a serine residue, do not produce $\mathrm{H}_{2} \mathrm{~S}$ (i.e., the levels of bound sulfane sulfur remain at control levels). We concluded that $\mathrm{H}_{2} \mathrm{~S}$ produced by enzymes is stored as bound sulfane sulfur in cells.

Does bound sulfane sulfur release enough $\mathrm{H}_{2} \mathrm{~S}$ with appropriate timing for the exertion of $\mathrm{H}_{2} \mathrm{~S}$ activity? Lysates of neurons and astrocytes release $\mathrm{H}_{2} \mathrm{~S}$ in the presence of endogenous concentrations of cysteine and glutathione at $\mathrm{pH} 8.4$ or when dihydrolipoic acid (DHLA) is present at $\mathrm{pH} 8.0 .^{22), 39)}$ When neurons are excited, $\mathrm{K}^{+}$is released and the extracellular concentration of $\mathrm{K}^{+}$reaches $10-12 \mathrm{mM}$, which depolarizes the membrane potential of surrounding astrocytes. During membrane repolarization, $\mathrm{Na}^{+} /$ $\mathrm{HCO}_{3}{ }^{-}$transporters are activated, shifting the intracellular $\mathrm{pH}$ to alkaline, which releases $\mathrm{H}_{2} \mathrm{~S}$ from bound sulfane sulfur. ${ }^{40)}$ However, we were unable to detect the release of $\mathrm{H}_{2} \mathrm{~S}$ from astrocytes. ${ }^{22)}$ Further investigations are required to determine whether bound sulfane sulfur is an $\mathrm{H}_{2} \mathrm{~S}$ store in cells.

3.3. Free $\mathbf{H}_{2}$ S. The cellular concentration of free $\mathrm{H}_{2} \mathrm{~S}$ can change significantly in a short period because (1) $\mathrm{H}_{2} \mathrm{~S}$ is produced and degraded by enzymes, (2) the sulfur of $\mathrm{H}_{2} \mathrm{~S}$ is incorporated into cysteine residues after being oxidized to $\mathrm{H}_{2} \mathrm{~S}_{\mathrm{n}}$, and (3) the reaction between thiol and $\mathrm{H}_{2} \mathrm{~S}_{n}$ releases $\mathrm{H}_{2} \mathrm{~S}$. Although local changes in $\mathrm{H}_{2} \mathrm{~S}$ concentration are not well understood, steady state concentrations have been measured. Furne et al. ${ }^{34)}$ vigorously mixed brain homogenates with phosphate buffer ( $\mathrm{pH} 5.7)$ and measured the released gases with gas chromatography. At this $\mathrm{pH}$, more than $95 \%$ of $\mathrm{H}_{2} \mathrm{~S}$ remained as $\mathrm{H}_{2} \mathrm{~S}$ gas without the release of $\mathrm{H}_{2} \mathrm{~S}$ from acid-labile 
sulfur. The endogenous concentration of $\mathrm{H}_{2} \mathrm{~S}$ in the brain was determined to be $14 \mathrm{nM}$ via this method. Using a modified method, Furne et al. ${ }^{41)}$ later found approximately $1 \mu \mathrm{M}$ in the aorta and approximately $7 \mathrm{nM}$ in the blood. The accuracy of the measurements obtained using this method depends on the efficiency of $\mathrm{H}_{2} \mathrm{~S}$ transfer from tissues into the gas space. By contrast, polarographic measurements by Whitfield et $a{ }^{42)}$ detected no sulfide in the blood of several species.

Wintner et al. ${ }^{35)}$ detected $7 \mu \mathrm{M} \mathrm{H}_{2} \mathrm{~S}$ in blood by mixing monobromobimane, a fluorescent dye that binds to thiols, with blood and analyzing it with highperformance liquid chromatography (HPLC). Shen et al. ${ }^{43), 44)}$ used this method to measure $\mathrm{H}_{2} \mathrm{~S}$ concentrations in mice and humans and detected 0.7 and $0.2 \mu \mathrm{M}$, respectively. These values are approximately 30-1000 times greater than those obtained by Furne et al. ${ }^{34), 41)}$ However, monobromobimane complexed with other thiols, which has the same HPLC retention time as monobromobimane complexed with $\mathrm{H}_{2} \mathrm{~S}$, may cause overestimation of the value. ${ }^{35)}$

We mixed brain homogenates with silver powder, which reacts with $\mathrm{H}_{2} \mathrm{~S}$ to produce silver sulfide on the surface of the powder. After washing for complete removal of proteins, which may contain acid-labile sulfur, the silver powder was exposed to thiourea and $\mathrm{H}_{2} \mathrm{SO}_{4}$ to recover $\mathrm{H}_{2} \mathrm{~S}$ from silver sulfide. The amount of $\mathrm{H}_{2} \mathrm{~S}$ was then measured with gas chromatography. In this method, the steady-state level of $\mathrm{H}_{2} \mathrm{~S}$ in the brain was under the detectable concentration of $25 \mathrm{nM} /$ tube, corresponding to $9.2 \mu \mathrm{M}$ in the brain. $^{22)}$

The results obtained with these three methods show that free $\mathrm{H}_{2} \mathrm{~S}$, like $\mathrm{NO}$, is maintained at low steady-state concentrations. The repetitive application of $\mathrm{H}_{2} \mathrm{~S}$ to astrocytes causes desensitization and a drop in $\mathrm{Ca}^{2+}$ influx. Thus, free $\mathrm{H}_{2} \mathrm{~S}$ must apparently be maintained in cells at low levels for proper cellular response to $\mathrm{H}_{2} \mathrm{~S}$. ${ }^{45)}$

\section{4. $\mathrm{H}_{2} \mathrm{~S}$ production}

$\mathrm{H}_{2} \mathrm{~S}$ is produced by three enzymes - CBS, CSE, and 3MST - along with CAT, which is identical to aspartate aminotransferase. $\mathrm{H}_{2} \mathrm{~S}$ is also produced from D-cysteine via the D-amino acid oxidase (DAO)/3MST pathway (Fig. 6).

4.1. CBS. Since our demonstration that CBS is an $\mathrm{H}_{2} \mathrm{~S}$-producing enzyme, ${ }^{19)}$ the properties of this enzyme have been studied extensively. CBS catalyzes pyridoxal 5'-phosphate (PLP)-dependent $\beta$-replacement reactions to produce $\left.\mathrm{H}_{2} \mathrm{~S} .{ }^{46)}, 47\right)$
Cysteine + homocysteine $\rightarrow$ cystathionine $+\mathrm{H}_{2} \mathrm{~S}$ [3]

Cysteine $\rightarrow$ serine $+\mathrm{H}_{2} \mathrm{~S}$

Cysteine $\rightarrow$ lanthionine $+\mathrm{H}_{2} \mathrm{~S}$

As described in the previous section, free $\mathrm{H}_{2} \mathrm{~S}$ is maintained at low concentrations in the steady state. For $\mathrm{H}_{2} \mathrm{~S}$ to function as a signaling molecule, its concentrations must be controlled by physiological stimuli, including substances that regulate enzyme activity.

One of the greatest effectors of $\mathrm{H}_{2} \mathrm{~S}$ production is S-adenosyl methionine (SAM). ${ }^{19), 48)}$ Shan et al. ${ }^{49)}$ demonstrated the mechanism through which SAM enhances CBS activity. The catalytic site, which is located at the center of the enzyme, is covered by the carboxyl-terminal SAM domain in the absence of SAM. SAM binding releases the domain and exposes the catalytic site, thereby activating the enzyme. $\mathrm{H}_{2} \mathrm{~S}$ production is also greatly enhanced in the presence of homocysteine and cysteine compared with cysteine alone, as shown in Eq. [3]. ${ }^{46), 47)}$

CBS activity is regulated through glutathionylation, which is a post-transcriptional modification of protein cysteine residues with the addition of glutathione. Glutathionylation of cysteine 346 increases CBS activity threefold. ${ }^{50)}$ By contrast, the binding of $\mathrm{NO}$ or $\mathrm{CO}$ to the heme group at the amino terminus of CBS suppresses CBS activity. ${ }^{51)}$ This regulation plays a key role in microcirculation in the brain. ${ }^{52)}$ During hypoxia, the suppression of CBS by $\mathrm{CO}$ is reversed by decreased production of $\mathrm{CO}$ by heme oxygenase- 2 in neurons. $\mathrm{H}_{2} \mathrm{~S}$ produced by CBS localized in astrocytes, which surround capillaries, relaxes capillary walls to increase blood flow. Thus, this mechanism may compensate for deficiencies in $\mathrm{O}_{2}$ supply. Combinations of these enhancers and suppressers may cause dynamic changes in the activity of CBS.

The balance between $\mathrm{H}_{2} \mathrm{~S}$ production and clearance also plays an important role in controlling $\mathrm{H}_{2} \mathrm{~S}$ concentration. ${ }^{53), 54)} \mathrm{H}_{2} \mathrm{~S}$ is cleared by mitochondrial enzymes such as sulfide-quinone oxidoreductase (SQR), sulfur dioxygenase, and rhodanese. However, the regulation of these enzymes is poorly understood. ${ }^{55)-57)}$

We examined the developmental and pathological changes in the localization of CBS in the brain. CBS is mainly localized to cerebellar Bergmann glia and astrocytes. ${ }^{58), 59)}$ At early developmental stages, CBS is expressed in neuroepithelial cells in the ventricular zone, but radial glial cells and astrocytes express CBS during the late embryonic and neonatal 


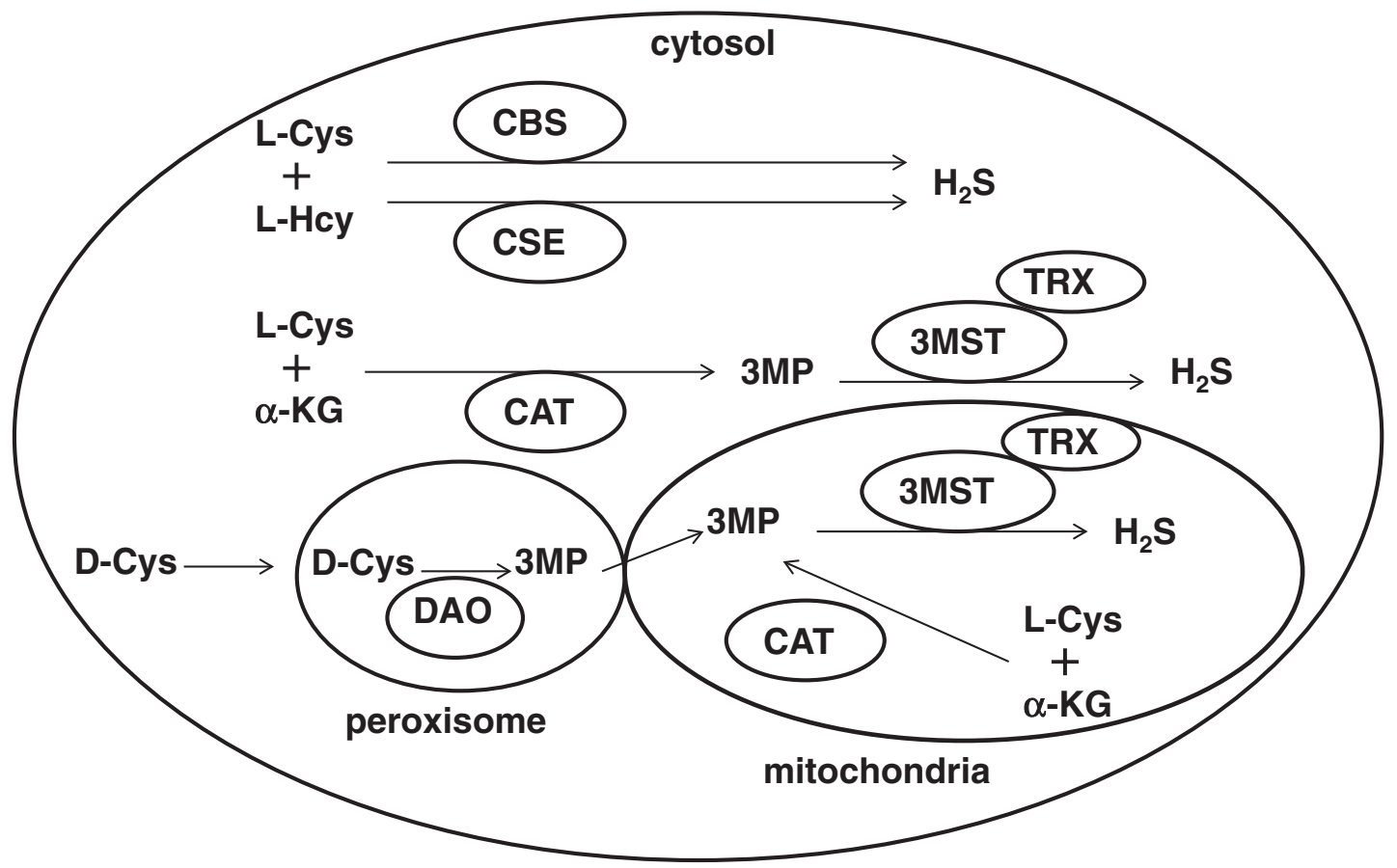

Fig. 6. $\mathrm{H}_{2} \mathrm{~S}$-producing pathways. CBS and CSE are localized to cytosol and produce $\mathrm{H}_{2} \mathrm{~S}$ from L-cysteine alone or L-cysteine along with L-homocysteine. 3MST and CAT are localized to both cytosol and mitochondria. L-cysteine and $\alpha$-ketoglutarate are metabolized by CAT to 3-MP, which is a substrate for $3 \mathrm{MST}$ to produce $\mathrm{H}_{2} \mathrm{~S}$. Thioredoxin interacts with $3 \mathrm{MST}$ to produce $\mathrm{H}_{2} \mathrm{~S}$ (see also Fig. 7 ). D-Cysteine is metabolized in peroxisomes by DAO to $3 \mathrm{MP}$, which is transported into mitochondria via a specific form of the vesicular transport. In mitochondria, $3 \mathrm{MP}$ is metabolized by $3 \mathrm{MST}$ to $\mathrm{H}_{2} \mathrm{~S}$. Peroxisome and mitochondria are in close vicinity or have a physical contact.

periods. CBS expression is up-regulated in reactive astrocytes. This up-regulation is induced by epidermal growth factor, transforming growth factor- $\alpha$, cyclic adenosine monophosphate, and dexamethasone. In CBS knockout mice, which show abnormal lipid metabolism in the liver, cerebellar morphological abnormalities are significant. ${ }^{58), 60)}$ Although the localization of CBS to cerebellar Purkinje cells and hippocampal neurons has also been reported, ${ }^{61)}$ we were unable to find CBS in these neurons even with the antibody used by Robert et al. ${ }^{58)}$

CBS is encoded on chromosome 21 (21q22.3), which is trisomy in Down syndrome (DS). Therefore, CBS expression is expected to be 1.5 times higher in people with DS than in normal individuals. However, our measurements showed that CBS in DS brains is approximately three times higher than that in normal individuals. ${ }^{59)}$ Moreover, DS patients are predisposed to Alzheimer's disease, and CBS is localized to astrocytes and astrocytes surrounding senile plaques in Alzheimer brains in individuals with DS. A polymorphism in the CBS allele is significantly underrepresented in children with a high intelligence quotient, suggesting that CBS may influence cognitive function. ${ }^{62)}$ The overexpression of CBS may cause developmental abnormalities in cognition in children with DS that may in turn lead to Alzheimer's disease in adulthood. ${ }^{59)}$

4.2. CSE. Since our demonstration that CSE is an $\mathrm{H}_{2} \mathrm{~S}$-producing enzyme in smooth muscle tissues ${ }^{23)}$ the localization and activity of this enzyme have been studied extensively. CSE produces $\mathrm{H}_{2} \mathrm{~S}$ via the PLP-dependent $\alpha, \beta$-elimination reaction with cysteine. ${ }^{47), 63), 64)}$

Cysteine + homocysteine

$$
\rightarrow \text { cystathionine }+\mathrm{H}_{2} \mathrm{~S}
$$

Homocysteine + homocysteine

$$
\rightarrow \text { homolanthionine }+\mathrm{H}_{2} \mathrm{~S}
$$

Cysteine + cysteine $\rightarrow$ lanthionine $+\mathrm{H}_{2} \mathrm{~S} \quad$ [8]

Yang et al. ${ }^{65)}$ reported that the activity of CSE is regulated by $\mathrm{Ca}^{2+} /$ calmodulin. However, although CSE is localized in the cytosol, they examined its regulation in the presence of $1-2 \mathrm{mM} \mathrm{Ca}^{2+}$, which is the extracellular $\mathrm{Ca}^{2+}$ concentration. The intracellular $\mathrm{Ca}^{2+}$ concentration is approximately $100 \mathrm{nM}$ 
in steady-state cells and increases up to $3 \mu \mathrm{M}$ in cells such as excited neurons. Our re-evaluation showed that CSE activity is regulated by $\mathrm{Ca}^{2+}$ but in a manner different from that reported in the Yang et al. study and that calmodulin is not involved in this regulation. ${ }^{66)}$ In the presence of PLP, the $\mathrm{H}_{2} \mathrm{~S}$ producing activity of $\mathrm{CSE}$ is at its maximum potential in the absence of $\mathrm{Ca}^{2+}$. It is suppressed by $\mathrm{Ca}^{2+}$ in a concentration-dependent manner up to $300 \mathrm{nM}$, and this suppressing state is maintained at higher $\mathrm{Ca}^{2+}$ concentrations. These observations suggest that $\mathrm{H}_{2} \mathrm{~S}$ may be constitutively produced by CSE in steady-state cells, whereas production is suppressed when intracellular $\mathrm{Ca}^{2+}$ concentrations are elevated. ${ }^{66)}$

CSE has been found in vascular smooth muscle but not in the endothelium. ${ }^{23), 26), 67)}$ A study by Yang et $a l^{65)}$ reported that CSE is also localized to the vascular endothelium; however, their previous in situ hybridization and western blot analyses, as well as our immunohistochemical analysis and that of Olson et al. ${ }^{68)}$ showed that CSE is localized only to the smooth muscle, not the endothelium. ${ }^{26), 67), 68)}$ This finding was confirmed by showing that the lysates of endothelium did not produce $\mathrm{H}_{2} \mathrm{~S}$ with cysteine alone, which would have occurred if CSE were present. By contrast, endothelial lysates required $\alpha$-ketoglutarate and cysteine, both of which are substrates for CAT, for $\mathrm{H}_{2} \mathrm{~S}$ production. ${ }^{67)}$ These observations suggest that 3MST and CAT are localized to the endothelium to produce $\mathrm{H}_{2} \mathrm{~S}$.

Because $\mathrm{H}_{2} \mathrm{~S}$ relaxes vascular smooth muscle, CSE knockout mice were expected to be hypertensive. Of two lines of CSE knockout mice studied, one was hypertensive and the other was not. ${ }^{65), 69)}$ It is reasonable that the knockout of a single $\mathrm{H}_{2} \mathrm{~S}$ producing enzyme, CSE, is inadequate to change blood pressure significantly because the $\mathrm{H}_{2} \mathrm{~S}$-producing 3MST/CAT pathway and CBS reportedly localize in the vascular endothelium. ${ }^{67), 68)}$ The 3MST/ CAT pathway, CBS, or both may compensate for the loss of CSE. Further studies are required to determine which enzymes are involved in the regulation of vascular tone (see Fig. 3).

We found that the promoter region of the CSE gene has an SP1 binding site that is activated by the multifunctional, proinflammatory cytokine tumor necrosis factor $\alpha{ }^{70}$ ) This site was later found to play a critical role not only in the expression of CSE but also in the antiapoptotic action of $\mathrm{H}_{2} \mathrm{~S}$ and the differentiation of smooth muscle ${ }^{71), 72)}$ (Fig. 7). Tumor necrosis factor $\alpha$ increases the production of
CSE and activates I $\kappa$ B kinase, which phosphorylates $\mathrm{I} \kappa \mathrm{B}$ to release its binding partner nuclear factor- $\kappa \mathrm{B}$ $(\mathrm{NF}-\kappa \mathrm{B})$ and expose its nuclear localization signal. $\mathrm{H}_{2} \mathrm{~S}$ produced by CSE adds sulfur to the cysteine residues of $\mathrm{NF}-\kappa \mathrm{B}$, which facilitates the nuclear translocation of NF- $\kappa \mathrm{B}$ and activation of the transcription of antiapoptotic genes. ${ }^{72)}$

Because CSE is not detected with western blot analysis in the brain and $\mathrm{H}_{2} \mathrm{~S}$ production in the brain is not suppressed by propargylglycine, an inhibitor selective to CSE, it appears that this enzyme contributes little to $\mathrm{H}_{2} \mathrm{~S}$ production in the brain. ${ }^{19), 70), 73)}$ However, contradictory observations have recently been reported. Specifically, CSE expression in the brains of Huntington model mice is markedly lower than that in wild-type brains. ${ }^{74)}$

4.3. 3MST and CAT. Initially, only CBS and CSE were recognized as $\mathrm{H}_{2} \mathrm{~S}$-producing enzymes. Because CSE was not found in the brain, we thought that $\mathrm{CBS}$ was a unique $\mathrm{H}_{2} \mathrm{~S}$-producing enzyme in brain tissue. ${ }^{19), 70)}$ However, we found that the brains of CBS knockout mice produced $\mathrm{H}_{2} \mathrm{~S}$, which suggested that a third $\mathrm{H}_{2} \mathrm{~S}$-producing enzyme is present in the brain. The activity for this enzyme was localized to mitochondria and synaptosomes, and cysteine and another factor (present with molecular weight less than $3 \mathrm{kDa}$ in cytosol) were required to produce $\mathrm{H}_{2} \mathrm{~S}$. A possible alternative to CBS for $\mathrm{H}_{2} \mathrm{~S}$ production in the brain was $3 \mathrm{MST} .{ }^{75)-77)}$ A substrate of 3MST, 3-mercaptopyruvate (3MP), is provided via the metabolism of cysteine and $\alpha$-ketoglutarate by CAT. 3MST and CAT were found in both synaptosomes and mitochondria, and the factor present with molecular weight less than $3 \mathrm{kDa}$ was $\alpha$-ketoglutarate. ${ }^{38)}$

$3 \mathrm{MST}$ produces $\mathrm{H}_{2} \mathrm{~S}$ from $3 \mathrm{MP}$, which is produced from cysteine and $\alpha$-ketoglutarate by CAT (see Fig. 6).

$$
\begin{aligned}
& \text { CAT: cysteine }+\alpha \text {-ketoglutarate } \\
& \quad \rightarrow 3 \mathrm{MP}+\text { glutamate } \\
& \text { 3MST: } 3 \mathrm{MP} \rightarrow \text { pyruvate }+\mathrm{H}_{2} \mathrm{~S}
\end{aligned}
$$

Although 3MST is a ubiquitous enzyme, its levels vary among tissues. High expression occurs in the liver, large intestine, and kidney. ${ }^{78)}$ In the brain, it localizes to neurons such as cerebellar Purkinje cells, mitral cells in the olfactory bulb, hippocampal pyramidal neurons, and astrocytes. ${ }^{38), 79)}$ Unlike the cytosol, mitochondria contain concentrations of cysteine that are sufficiently high (approximately $1 \mathrm{mM}$ ) for $\mathrm{H}_{2} \mathrm{~S}$ production via the $3 \mathrm{MST} / \mathrm{CAT}$ pathway. ${ }^{80), 81)}$ 


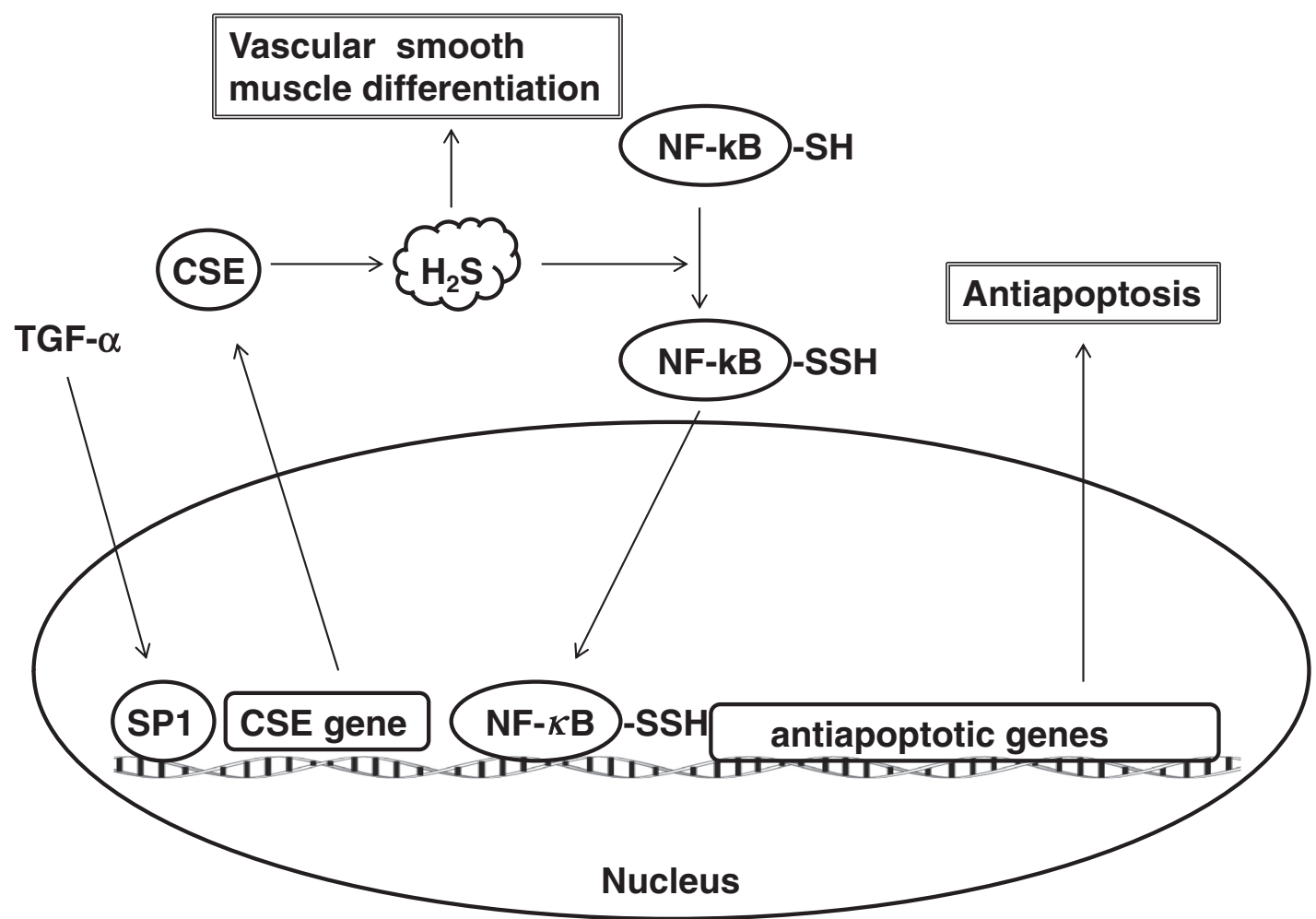

Fig. 7. Transcription factor SP-1 up-regulates the CSE gene. $\mathrm{H}_{2} \mathrm{~S}$ produced by CSE, whose transcription is increased by TGF- $\alpha$ mediated through SP1 binding activation, sulfurates (sulfhydrates) NF- $\kappa$ B to make it translocate into the nucleus and up-regulate antiapoptotic genes. Increased production of CSE by the activation of SP1 also plays an important role in the vascular smooth muscle differentiation.

CBS and CSE do not require a reducing substance such as DTT for $\mathrm{H}_{2} \mathrm{~S}$ production, whereas 3MST does. Because the required endogenous reducing substance was unknown until we identified thioredoxin, the $3 \mathrm{MST} / \mathrm{CAT}$ pathway was not recognized as a $\mathrm{H}_{2} \mathrm{~S}$-producing pathway. However, the 3MST orthologue of Trichomonas vaginalis catalyzes the formation of thioredoxin persulfide, and 3MST interacts with thioredoxin, which has two redox-active cysteine residues in its active site. ${ }^{82-84)}$ Given these observations, we hypothesized that thioredoxin may be the endogenous reducing substance associated with $3 \mathrm{MST}$ that allows for $\mathrm{H}_{2} \mathrm{~S}$ production. Thioredoxin has two forms, thioredoxin 1 and 2, that are localized in the cytosol and mitochondria, respectively. ${ }^{84), 85)}$ The two cysteine residues at the active site are conserved among different species, and similar to the bacterial thioredoxin that we used, thioredoxin 2 is resistant to oxidative stress. Given that thioredoxin is readily oxidized, it requires a reductase to maintain its reduced form. The mammalian thioredoxin reductase is a selenoprotein that cannot be produced in bacteria. ${ }^{86)}$ Therefore, we used lysates of A549 human lung adenocarcinoma cells, which have an abundant supply of thioredoxin reductase, with nicotinamide adenine dinucleotide phosphate (NADPH) to reduce thioredoxin. ${ }^{87}$ ) Approximately $20 \mu \mathrm{M}$ thioredoxin is present in cells, ${ }^{84}$ ) and $\mathrm{H}_{2} \mathrm{~S}$ is produced in fourfold greater amounts in the presence of thioredoxin than in the presence of the same concentration of DTT ${ }^{39)}$ (Figs. 6 and 8).

DHLA, which is present at levels of approximately $40 \mu \mathrm{M}$ in the brain, exhibits efficiency similar to that of DTT for the production of $\mathrm{H}_{2} \mathrm{~S}$ by 3MST. ${ }^{39), 88), 89)}$ Other physiological reducing substances such as glutathione (GSH), cysteine, NADPH, nicotinamide adenine dinucleotide, and coenzyme A show no effect on the production of $\mathrm{H}_{2} \mathrm{~S}$ by $3 \mathrm{MST}$. Dithiols such as DTT and DHLA have redox potentials that range from -0.29 to $-0.33 \mathrm{~V}$, and the redox potential of the active-site dithiol of thioredoxin is $-0.29 \mathrm{~V} .{ }^{90), 91)}$ The reducing potentials of monothiols such as GSH, cysteine, and coenzyme A range from -0.22 to $-0.35 \mathrm{~V},{ }^{92)}$ and those of 


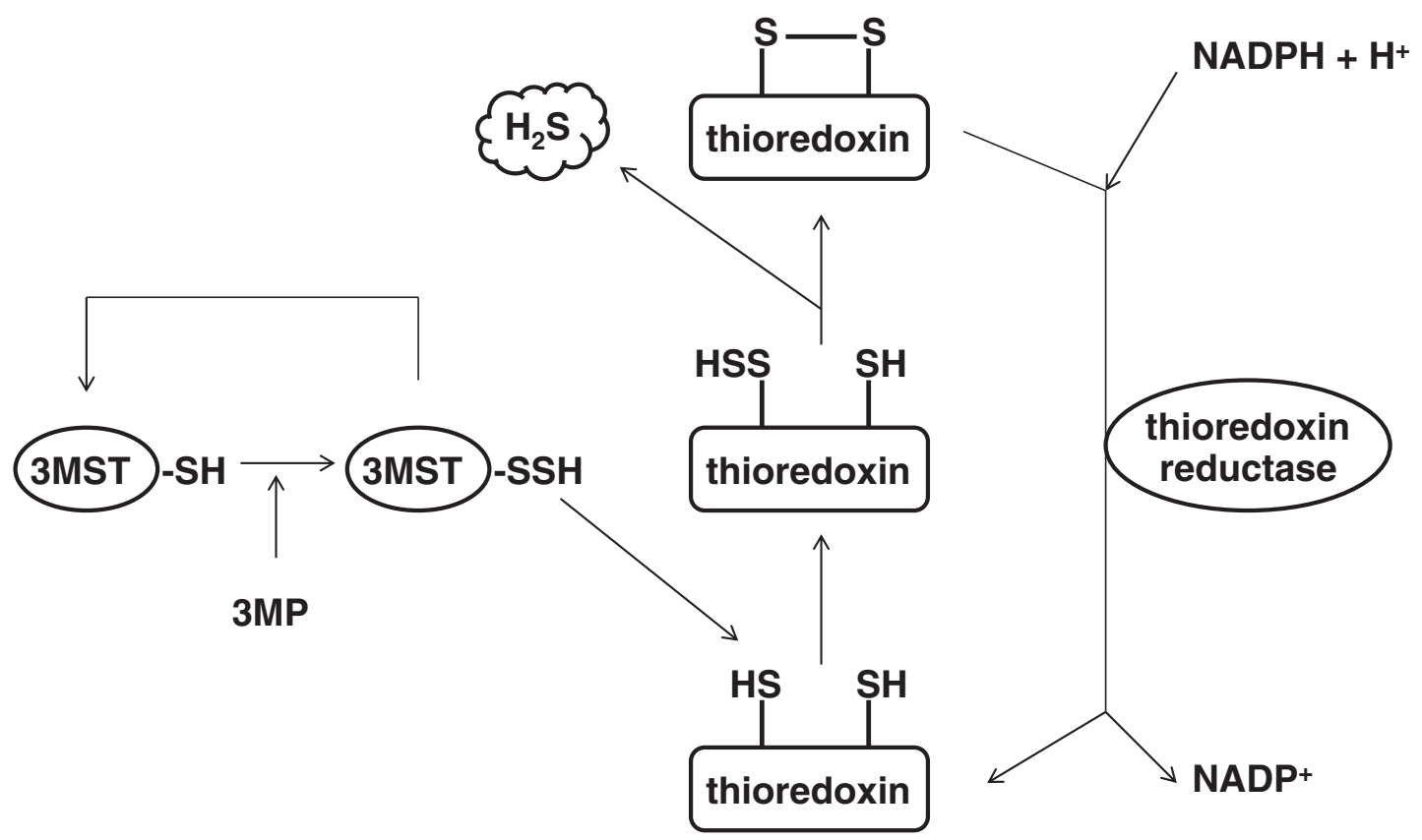

Fig. 8. 3MST produces $\mathrm{H}_{2} \mathrm{~S}$ with thioredoxin as an acceptor of sulfane sulfur. 3MST receives sulfur from 3MP to produce 3MST persulfide, which is transferred to one of the thiols in thioredoxin to generate thioredoxin persulfide. The remaining thiol reacts with persulfide to release $\mathrm{H}_{2} \mathrm{~S}$. Oxidized thioredoxin is reduced back to its reduced form by thioredoxin reductase.

nicotinamide adenine dinucleotide and NADPH are -0.320 and $-0.324 \mathrm{~V}$, respectively. ${ }^{93)}$ These data show that reducing potential has no correlation with the capacity of these substances to affect $\mathrm{H}_{2} \mathrm{~S}$ production by 3MST, but dithiols such as DTT, DHLA, and thioredoxin have critical effects. ${ }^{39), 83)}$

4.4. 3MST and DAO. Because mammalian enzymes generally metabolize L-amino acids with few exceptions (D-serine and D-aspartate), ${ }^{94), 95)}$ we applied D-cysteine to brain homogenates as a negative control to L-cysteine for $\mathrm{H}_{2} \mathrm{~S}$ production. Unexpectedly, $\mathrm{H}_{2} \mathrm{~S}$ was produced from D-cysteine. ${ }^{78)}$ Although the production of $\mathrm{H}_{2} \mathrm{~S}$ from D-cysteine has been studied in microorganisms and plants, ${ }^{96)}$ its production in mammals is not well understood. The production of $\mathrm{H}_{2} \mathrm{~S}$ from L-cysteine and D-cysteine has significantly different dependencies on $\mathrm{pH}$ and PLP. Because mitochondrial 3MST produces $\mathrm{H}_{2} \mathrm{~S}$ from 3MP, we searched for an enzyme that produces $3 \mathrm{MP}$ from D-cysteine. DAO has been proposed to produce $3 \mathrm{MP}$ in hepatocytes. ${ }^{97)}$ Indeed, our study showed that in the absence of $\mathrm{DAO}, \mathrm{H}_{2} \mathrm{~S}$ was not produced from D-cysteine and that indole-2-carboxylate, a DAO inhibitor, suppressed $\mathrm{H}_{2} \mathrm{~S}$ production from D-cysteine. ${ }^{78)}$ D-Cysteine is metabolized by DAO to achiral 3MP, which is a substrate of $3 \mathrm{MST}$ for the production of $\mathrm{H}_{2} \mathrm{~S}$ (see Fig. 6).

$$
\begin{aligned}
& \text { DAO: D-cysteine }+\mathrm{O}_{2}+\mathrm{H}_{2} \mathrm{O} \\
& \quad \rightarrow 3 \mathrm{MP}+\mathrm{H}_{2} \mathrm{O}_{2}+\mathrm{NH}_{3} \\
& \text { 3MST: } 3 \mathrm{MP} \rightarrow \text { pyruvate }+\mathrm{H}_{2} \mathrm{~S}
\end{aligned}
$$

3MST localizes to mitochondria, whereas DAO is present in peroxisomes. Mitochondria and peroxisomes exchange various metabolites via a specific form of vesicular trafficking, and they are usually in close proximity or physical contact with one another. ${ }^{98)} 3 \mathrm{MP}$ produced by DAO in peroxisomes is transferred via vesicular trafficking to mitochondria, in which $\mathrm{H}_{2} \mathrm{~S}$ is produced by $3 \mathrm{MST}$ (see Fig. 6).

$3 \mathrm{MST}$ is a ubiquitous enzyme, whereas DAO is localized to the brain and kidney. ${ }^{78)} \mathrm{H}_{2} \mathrm{~S}$ is produced from D-cysteine only in the kidney and the brain (mostly in the cerebellum). The production in the kidney is seven times that in the cerebellum. In the kidney, the production of $\mathrm{H}_{2} \mathrm{~S}$ from D-cysteine is approximately 80 times that from L-cysteine. ${ }^{78)}$ Compared with L-cysteine administration, the oral administration of D-cysteine to mice increases the levels of bound sulfane sulfur, a potential intracellular store of $\mathrm{H}_{2} \mathrm{~S}$, and protects the kidneys from ischemiareperfusion injury much more efficiently. D-Cysteine may provide a new therapeutic approach to mitigate ischemia-reperfusion injury by delivering $\mathrm{H}_{2} \mathrm{~S}$ to specific tissues such as the kidney and cerebellum. 
As a source of D-cysteine, approximately 20$40 \%$ of L-cysteine is converted to D-cysteine by heat and alkaline conditions during food processing. This D-cysteine is easily absorbed through the gastrointestinal tract and readily enters the bloodstream. ${ }^{99)-101)}$ Alternatively, L-cysteine may be converted to D-cysteine by a racemase via a process that has not been elucidated.

Recently, a bioluminescent method was developed to measure the real-time activity and localization of DAO. In this method, the highly selective condensation reaction between D-cysteine and 6hydroxy-2-cyanobenzothiazole to form D-luciferin is used for the sensitive measurement of DAO activity. ${ }^{102)}$

\section{From toxin to cytoprotectant}

Because $\mathrm{H}_{2} \mathrm{~S}$ is a toxic gas, it was generally not predicted to have a cytoprotective effect. However, our research indicated that high concentrations of $\mathrm{H}_{2} \mathrm{~S}$ in the primary cultures of neurons did not cause cell death but rather protected them from oxidative insults or oxidative glutamate toxicity. ${ }^{103), 104)}$ There are two forms of glutamate toxicity: excitotoxicity and oxidative toxicity. Excitotoxicity is caused by the long-lasting activation of NMDA receptors through which $\mathrm{Ca}^{2+}$ enters cells at levels beyond cell tolerance. ${ }^{105)}$ Oxidative toxicity is caused by high concentrations of glutamate suppressing the cystine/ glutamate antiporter, which imports cystine into cells with reciprocal export of glutamate. ${ }^{106)}$ Cystine is reduced to cysteine inside cells. The decrease in the intracellular cysteine concentration decreases the production of GSH, a major intracellular antioxidant, which makes cells vulnerable to oxidative stress.

Embryonic neurons, which do not express NMDA receptors, provide a good model for oxidative glutamate toxicity because they are not disturbed by excitotoxicity. ${ }^{106)}$ Cultures of embryonic neurons die $24 \mathrm{~h}$ after being exposed to high concentrations of glutamate but survive in the presence of $\mathrm{H}_{2} \mathrm{~S} .{ }^{103)}$ This cryoprotection by $\mathrm{H}_{2} \mathrm{~S}$ is effective even $8 \mathrm{~h}$ after the application of glutamate, although the efficiency declines with time. ${ }^{104)}$ Because $\mathrm{H}_{2} \mathrm{~S}$ readily evaporates from culture medium (i.e., half-life of approximately $10 \mathrm{~min}^{42), 104)}$ ), its effect of making cells commit to resist oxidative stress occurs during this initial short exposure.

$\mathrm{H}_{2} \mathrm{~S}$ exerts its cytoprotective effect by increasing GSH production and scavenging reactive oxygen species. GSH, a tripeptide consisting of glutamate, cysteine, and glycine, is produced by two enzymes, glutamate-cysteine ligase (GCL), also called $\gamma$ glutamyl cysteine synthetase, and GSH synthetase, which adds glycine to the GCL product $\gamma$-glutamyl cysteine. $\mathrm{H}_{2} \mathrm{~S}$ enhances GCL activity and potentiates the activity of the cystine/glutamate antiporter as well as the cysteine transporter, both of which increase intracellular concentrations of cysteine. ${ }^{103)}$ Through these effects, $\mathrm{H}_{2} \mathrm{~S}$ increases the production of GSH (Fig. 9).

$\mathrm{H}_{2} \mathrm{~S}$ produced by $3 \mathrm{MST}$ in the mitochondrion suppresses oxidative stress in this organelle. ${ }^{107)}$ The endogenous concentrations of $\mathrm{H}_{2} \mathrm{~S}$ range from approximately $10 \mathrm{nM}$ to $3 \mu \mathrm{M}$, whereas those of GSH are 1-10 mM. Therefore, $\mathrm{H}_{2} \mathrm{~S}$ suppresses oxidative stress mainly by increasing GSH production (see Fig. 9).

The discovery of the neuroprotective effect of $\mathrm{H}_{2} \mathrm{~S}$ led to the identification of protective effects from ischemic insults in the heart and kidney and from high-fat diet-induced glucotoxicity in pancreatic $\beta$ cells. ${ }^{108)-111)} \mathrm{H}_{2} \mathrm{~S}$ limits infarct size and preserves cardiac function by inhibiting myocardial inflammation and apoptosis and preserving mitochondrial structure and function. ${ }^{108)}$ With respect to renal protection during ischemic insult, $\mathrm{H}_{2} \mathrm{~S}$ attenuates the phosphorylation of mitogen-activated protein kinases as well as the activation of NF- $\kappa \mathrm{B}$ and caspase- 3 and suppression of Bcl-2 expression. ${ }^{109)}$

Other mechanisms for the cytoprotective effect of $\mathrm{H}_{2} \mathrm{~S}$ have also been identified. For instance, retinal tissue is susceptible to oxidative stress because it consumes large quantities of $\mathrm{O}_{2}$ and is constantly exposed to light. Exposure of the retina to excessive light results in photoreceptor cell damage, which is caused by various factors, including elevated intracellular concentrations of $\mathrm{Ca}^{2+}$ and reactive oxygen species. In the retina, $\mathrm{H}_{2} \mathrm{~S}$ activates vacuolar-type $\mathrm{H}^{+}$-ATPase in horizontal cells to release $\mathrm{H}^{+}$, which suppresses $\mathrm{Ca}^{2+}$ channels in photoreceptor cells to maintain intracellular concentrations of $\mathrm{Ca}^{2+}$ at appropriately low levels. ${ }^{112)}$ Moreover, the regulation of endoplasmic reticulum (ER) stress contributes to the cytoprotective effect of $\mathrm{H}_{2} \mathrm{~S}$. After being produced in the ER, proteins are trafficked to the Golgi apparatus. Misfolded proteins trigger the unfolded protein response to start proapoptotic cascades. ${ }^{113)}$ ER stress increases the production of $\mathrm{H}_{2} \mathrm{~S}$, which inhibits protein tyrosine phosphatase (PTP). In turn, PTP inactivates protein kinase-like ER kinase to inhibit global translation by phosphorylating elF $2 \alpha$, which suppresses ER stress responses. ${ }^{114)}$

In addition to its cytoprotective effects, $\mathrm{H}_{2} \mathrm{~S}$ regulates bacterial resistance to antibiotics. Shatalin 


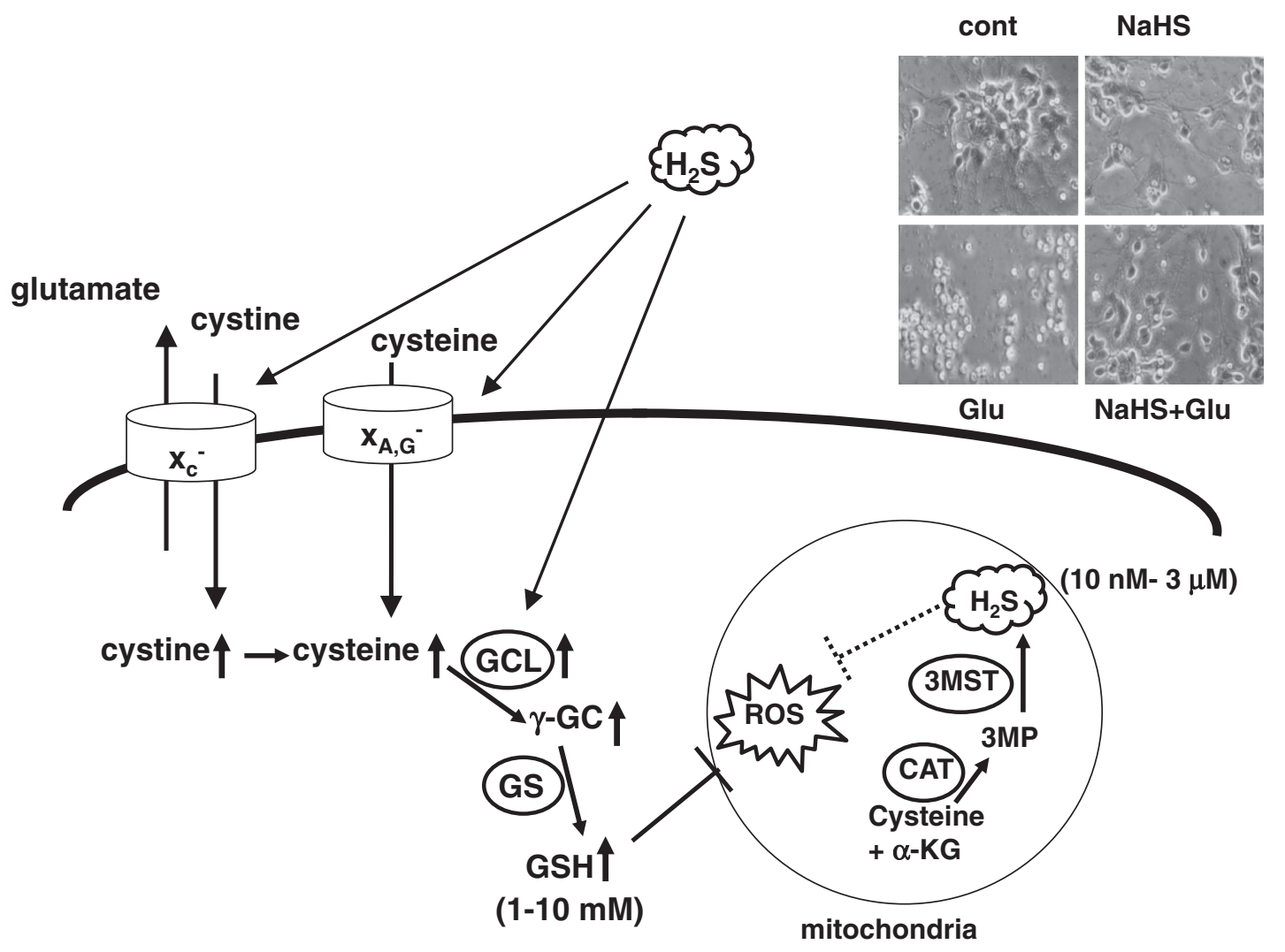

Fig. 9. Cytoprotective effect of $\mathrm{H}_{2} \mathrm{~S}$. $\mathrm{H}_{2} \mathrm{~S}$ protects embryonic neurons from oxidative stress induced by high concentrations of glutamate. $\mathrm{H}_{2} \mathrm{~S}$ enhances the activity of the cystine/glutamate antiporter and the cysteine transporter to increase the intracellular concentrations of cysteine. $\mathrm{H}_{2} \mathrm{~S}$ also enhances the activity of glutamate cysteine lygase (GCL) to produce $\gamma$-glutamylcysteine to which glycine is added by glutathione synthetase (GC) to generate glutathione (GSH). $\mathrm{H}_{2} \mathrm{~S}$ produced via the 3-mercaptopyruvate sulfurtransferase $(3 \mathrm{MST}) /(\mathrm{CAT})$ pathway scavenges reactive oxygen species (ROS), which are abundantly generated in mitochondria. The intracellular concentrations of GSH are $1-10 \mathrm{mM}$, while those of $\mathrm{H}_{2} \mathrm{~S}$ are only $10 \mathrm{nM}$ to $3 \mu \mathrm{M}$. $\mathrm{H}_{2} \mathrm{~S}$ efficiently suppresses oxidative stress by increasing the production of GSH rather than by scavenging ROS.

et al. ${ }^{115)}$ demonstrated that the inactivation of the bacterial homologues of CBS, CSE, and 3MST decreases the production of $\mathrm{H}_{2} \mathrm{~S}$, which increases the vulnerability of bacteria to antibiotics. The cytoprotective effect of $\mathrm{H}_{2} \mathrm{~S}$ appears to be a universal defense mechanism in organisms from bacteria to mammals. Bacteria also produce NO, and both $\mathrm{H}_{2} \mathrm{~S}$ and NO synergistically protect bacteria from antibiotics. Because bacterial CBS, CSE, and 3MST are evolutionarily distinct from their mammalian counterparts, they may be appropriate targets for the development of new classes of antibiotics. ${ }^{115)}$

\section{Regulation of synaptic transmission}

6.1. Enhancing the activity of NMDA receptors. To explore the mechanism for the facilitation of LTP induction by $\mathrm{H}_{2} \mathrm{~S}$, we examined the target of $\mathrm{H}_{2} \mathrm{~S}$ at the synapse. The activation of NMDA re- ceptors is required to induce LTP. Our observations showed that $\mathrm{H}_{2} \mathrm{~S}$ enhanced the activity of NMDA receptors but not that of $\alpha$-amino-3-hydroxy-5methyl-4-isoxazolepropionic acid receptors, another type of glutamate receptor ${ }^{19)}$ (see Fig. 1).

Aizenman et al. ${ }^{116)}$ demonstrated that the reduction by DTT of the cysteine disulfide bond at the hinge of the ligand-binding domain of NMDA receptors enhances the activity of the receptors. By contrast, $\quad \alpha$-amino-3-hydroxy-5-methyl-4-isoxazolepropionic acid receptors lack a corresponding cysteine disulfide bond. Because $\mathrm{H}_{2} \mathrm{~S}$ can reduce the cysteine disulfide bond, the enhancement of NMDA receptor activity is one of the $\mathrm{H}_{2} \mathrm{~S}$ effects that facilitates LTP induction. However, this was not the only effect of $\mathrm{H}_{2} \mathrm{~S}$. We found an inconsistency that introduces difficulty in explaining the induction of LTP solely by the reducing activity of $\mathrm{H}_{2} \mathrm{~S}$. DTT, 
which is a more efficient reducing agent than $\mathrm{H}_{2} \mathrm{~S}$, facilitated the induction of LTP, but a lower concentration of $\mathrm{H}_{2} \mathrm{~S}$ further facilitated the induction of LTP even after DTT treatment. ${ }^{19)}$ This discrepancy suggests that $\mathrm{H}_{2} \mathrm{~S}$ has an additional effect that DTT does not (see Fig. 1).

6.2. Activation of astrocytes surrounding synapses. Astrocytes, which are a type of glia, surround synapses and have neurotransmitter receptors. Typically, presynaptic neurons release a neurotransmitter to postsynaptic neurons and activate surrounding astrocytes as well. These activated astrocytes in turn release gliotransmitters into synapses to modulate their activity. We hypothesized that $\mathrm{H}_{2} \mathrm{~S}$ may have an effect on astrocytes that in turn modulates synaptic activity, which leads to the facilitation of LTP. We first observed that $\mathrm{H}_{2} \mathrm{~S}$ induces $\mathrm{Ca}^{2+}$ influx in astrocytes. ${ }^{45)}$ The responses were abolished in the absence of extracellular $\mathrm{Ca}^{2+}$ and by broad-spectrum transient receptor potential (TRP) channel inhibitors such as $\mathrm{La}^{3+}, \mathrm{Gd}^{3+}$, and ruthenium red, suggesting that $\mathrm{H}_{2} \mathrm{~S}$ activates TRP channels to induce $\mathrm{Ca}^{2+}$ influx. ${ }^{45)}$ Only glial fibrillary acidic protein-positive mature astrocytes respond to $\mathrm{H}_{2} \mathrm{~S}$; immature or reactive astrocytes induced by epidermal growth factor, transforming growth factor$\alpha$, cyclic adenosine monophosphate, or interleukin- $1 \beta$ do not. ${ }^{117)}$

6.3. Identification of $\mathbf{H}_{2} \mathbf{S}_{n}$. During the study of the effect of $\mathrm{H}_{2} \mathrm{~S}$ on astrocytes, we found that compared with $\mathrm{NaHS}$ (a sodium salt of $\mathrm{H}_{2} \mathrm{~S}$ ), sodium tri- and tetrasulfide $\left(\mathrm{Na}_{2} \mathrm{~S}_{3}\right.$ and $\mathrm{Na}_{2} \mathrm{~S}_{4}$; sodium salts of $\mathrm{H}_{2} \mathrm{~S}_{3}$ and $\mathrm{H}_{2} \mathrm{~S}_{4}$ ) induce $\mathrm{Ca}^{2+}$ influx in astrocytes much more potently. ${ }^{45), 118)-120)}$ Unlike $\mathrm{H}_{2} \mathrm{~S}, \mathrm{H}_{2} \mathrm{~S}_{\mathrm{n}}$ does not exist as a gas under physiological conditions. Therefore, $\mathrm{Na}_{2} \mathrm{~S}_{\mathrm{n}}$ is dissolved in water and dissociates to $\mathrm{H}^{+}$and $\mathrm{HS}_{\mathrm{n}}{ }^{-}$. Given that the applied concentrations of $\mathrm{Na}_{2} \mathrm{~S}_{\mathrm{n}}$ are low, the effect of $\mathrm{Na}^{+}$can be ignored.

$$
\mathrm{H}_{2} \mathrm{~S}_{\mathrm{n}} \rightarrow \mathrm{H}^{+}+\mathrm{HS}_{\mathrm{n}}{ }^{-}
$$

Comparison of the half-maximal effective concentration $\left(\mathrm{EC}_{50}\right)$ for the induction of $\mathrm{Ca}^{2+}$ influx of $\mathrm{Na}_{2} \mathrm{~S}_{3}\left(\mathrm{EC}_{50}=91 \mathrm{nM}\right)$ and $\mathrm{NaHS}\left(\mathrm{EC}_{50}=116 \mu \mathrm{M}\right)$ has shown that $\mathrm{Na}_{2} \mathrm{~S}_{3}$ is approximately 1000 times more potent than $\mathrm{NaHS}^{45), 120)}$ (Fig. 10).

While investigating the effects of NaHS on the induction of $\mathrm{Ca}^{2+}$ influx in astrocytes, we noticed that some solutions of NaHS, which are typically colorless, were yellowish. We realized that compared with colorless solutions, the yellow NaHS solutions had a greater effect on inducing $\mathrm{Ca}^{2+}$ influx. We speculated that the yellow color originated from elemental sulfur and that a synergy exists between $\mathrm{H}_{2} \mathrm{~S}$ and elemental sulfur that activates TRP channels. When elemental sulfur was dissolved in a solution of NaHS, the solution turned yellow and potently induced $\mathrm{Ca}^{2+}$ influx in astrocytes. Searcy and Lee ${ }^{121)}$ have reported that elemental sulfur dissolved in $\mathrm{Na}_{2} \mathrm{~S}$ solution, another sodium salt of $\mathrm{H}_{2} \mathrm{~S}$, generates $\mathrm{H}_{2} \mathrm{~S}_{\mathrm{n}}$ species $\left(\mathrm{Na}_{2} \mathrm{~S}_{3}\right.$ and sodium pentasulfide), and in 2006, we demonstrated that $\mathrm{Na}_{2} \mathrm{~S}_{3}$ and $\mathrm{Na}_{2} \mathrm{~S}_{4}$ induce $\mathrm{Ca}^{2+}$ influx much more potently than NaHS does by activating TRP channels. ${ }^{118)}$ Thus, it appears that it is not the synergy between elemental sulfur and $\mathrm{H}_{2} \mathrm{~S}$ but the effect of the $\mathrm{H}_{2} \mathrm{~S}_{\mathrm{n}}$ products from both agents that potently induces $\mathrm{Ca}^{2+}$ influx.

6.4. $\mathrm{H}_{2} \mathrm{~S}_{\mathrm{n}}$ activates TRP ankyrin 1 (TRPA1) channels in astrocytes. In 2008, Streng et al. ${ }^{122)}$ demonstrated that $\mathrm{H}_{2} \mathrm{~S}$ activates the TRPA1 channels of sensory neurons in the urinary bladder and that Chinese hamster ovary cells overexpressing TRPA1 channels respond to $\mathrm{H}_{2} \mathrm{~S}$. Ogawa et al. ${ }^{123)}$ found a similar result in dorsal root ganglion cells using TRPA1 knockout mice and TRPA1-overexpressing human embryonic kidney 293 cells. However, high concentrations of NaHS $(1-10 \mathrm{mM})$ were applied in these studies. $\mathrm{H}_{2} \mathrm{~S}$ is oxidized to $\mathrm{H}_{2} \mathrm{~S}_{\mathrm{n}}$ species with a varying number of sulfur atoms until the number of sulfur atoms reaches eight, at which point the sulfur molecules cyclize and precipitate. ${ }^{37), 124)}$ The number of sulfur atoms on $\mathrm{H}_{2} \mathrm{~S}_{\mathrm{n}}$ species under physiological conditions remains undetermined.

$$
\begin{aligned}
& 2 \mathrm{nH}_{2} \mathrm{~S}+1 / 2(2 \mathrm{n}-1) \mathrm{O}_{2} \\
& \quad \rightarrow \mathrm{H}_{2} \mathrm{~S}_{2 \mathrm{n}}+(2 \mathrm{n}-1) \mathrm{H}_{2} \mathrm{O} \\
& \mathrm{HS}^{-} \leftrightarrow \mathrm{HSS}^{-} \leftrightarrow \mathrm{HSSS}^{-} \leftrightarrow \ldots \leftrightarrow \mathrm{HS}_{7}{ }^{-} \rightarrow \mathrm{S}_{8}
\end{aligned}
$$

Therefore, a portion of NaHS may have been oxidized to $\mathrm{Na}_{2} \mathrm{~S}_{\mathrm{n}}$, which activated TRPA1 channels in previous studies. Taking these results and our previous observation into account, we hypothesized that $\mathrm{H}_{2} \mathrm{~S}_{\mathrm{n}}$ species activate TRPA1 channels in astrocytes.

A transcriptional database showed that TRPA1 messenger RNA is present below detectable levels in astrocytes, but immunohistochemical studies have thus far not indicated the location of TRPA1 channels in astrocytes. ${ }^{125), 126)}$ However, in 2012, Shigetomi et al. ${ }^{127)}$ demonstrated the existence of TRPA1 channels in astrocytes with western blot and functional analyses. Furthermore, the application of the TRPA1 channel-selective agonists allyl isothiocyanate and cinnamaldehyde induced $\mathrm{Ca}^{2+}$ 
A

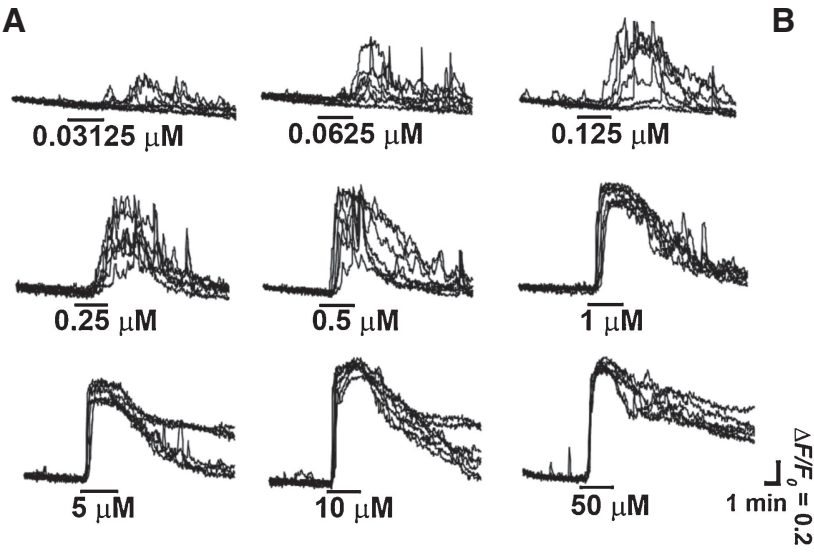

B

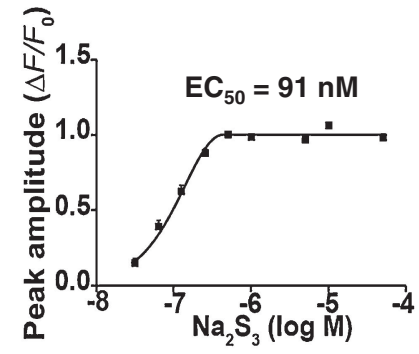

C

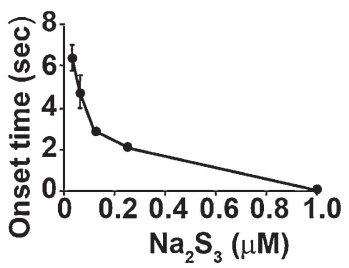

D

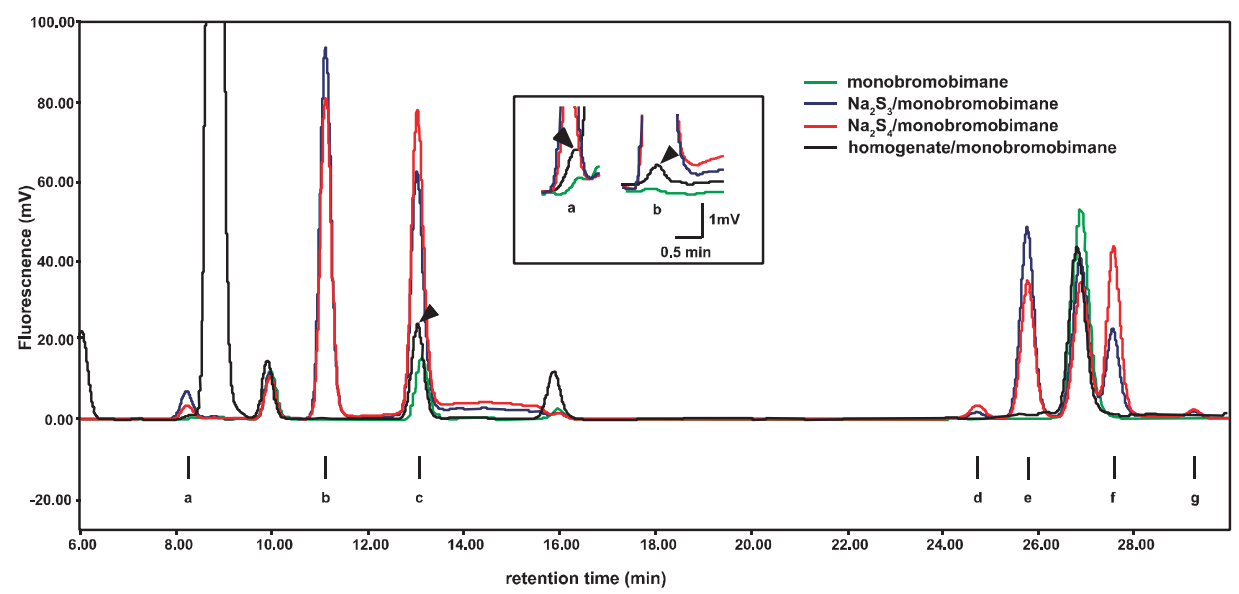

Fig. 10. Existence of $\mathrm{H}_{2} \mathrm{~S}_{\mathrm{n}}$ in the brain and the induction of $\mathrm{Ca}^{2+}$ influx in astrocytes. $\mathrm{H}_{2} \mathrm{~S}_{3}$ induces $\mathrm{Ca}^{2+}$ influx in astrocdytes in a dosedependent manner with $\mathrm{EC}_{50}=91 \mathrm{nM}(\mathrm{A}$ and $\mathrm{B})$. Because $\mathrm{H}_{2} \mathrm{~S}_{\mathrm{n}}$ are mixture of molecules with different number of sulfur atoms in equilibrium as shown in the Eq. [14], even the standard $\mathrm{Na}_{2} \mathrm{~S}_{3}$ and $\mathrm{Na}_{2} \mathrm{~S}_{4}$ exert several peaks at the same retention times. Brain samples contain $\mathrm{H}_{2} \mathrm{~S}_{\mathrm{n}}$ (Figures in 120 were modified).

influx and confirmed the existence of these channels in astrocytes. ${ }^{119), 120)}$ The responses to $\mathrm{Na}_{2} \mathrm{~S}_{3}$ and $\mathrm{Na}_{2} \mathrm{~S}_{4}$ were suppressed by the TRPA1 channelselective antagonists HC-030031 and AP-18 as well as by small interfering RNA selective to TRPA1 channels, which suggested that $\mathrm{H}_{2} \mathrm{~S}_{\mathrm{n}}$ species activate TRPA1 channels in astrocytes. ${ }^{120)}$

Ogawa et al. ${ }^{123)}$ determined the site within TRPA1 channels that was sensitive to high $\mathrm{H}_{2} \mathrm{~S}$ concentrations. They revealed that replacing two cysteine residues at the amino terminus of TRPA1 channels with serine causes an insensitivity to NaHS. The observation that the effect of NaHS was suppressed by the reducing agent DTT suggests that these two sensitive cysteine residues are sulfurated by $\mathrm{H}_{2} \mathrm{~S}_{\mathrm{n}}$ generated from NaHS, which results in a conformational change in the TRPA1 channels that leads to their activation. When the sulfurated cysteine residues are removed with DTT or glutathione, the channels return to their quiescent conformation (Fig. 11).

6.5. Endogenous $\mathrm{H}_{2} \mathrm{~S}_{\mathrm{n}}$ in the brain. We identified $\mathrm{H}_{2} \mathrm{~S}_{\mathrm{n}}$ in the brain by using HPLC to analyze samples derivatized with monobromobimane. ${ }^{120)}$ Because $\mathrm{H}_{2} \mathrm{~S}_{\mathrm{n}}$ species are mixture with various numbers of sulfur atoms in equilibrium, even the standard $\mathrm{Na}_{2} \mathrm{~S}_{3}$ and $\mathrm{Na}_{2} \mathrm{~S}_{4}$ exhibit several peaks. The endogenous level of a major $\mathrm{H}_{2} \mathrm{~S}_{\mathrm{n}}$ (i.e., a major peak observed in HPLC) is approximately $20 \mu \mathrm{M}$ in the brain (see Fig. 10). Identification of this $\mathrm{H}_{2} \mathrm{~S}_{n}$ is under investigation using liquid chromatography tandem-mass spectrometry.

6.6. Mechanism for the facilitation of LTP. As described in section $6.1, \mathrm{H}_{2} \mathrm{~S}$ reduces cysteine disulfide bonds at the ligand-binding domain of NMDA receptors to enhance the activity of the 


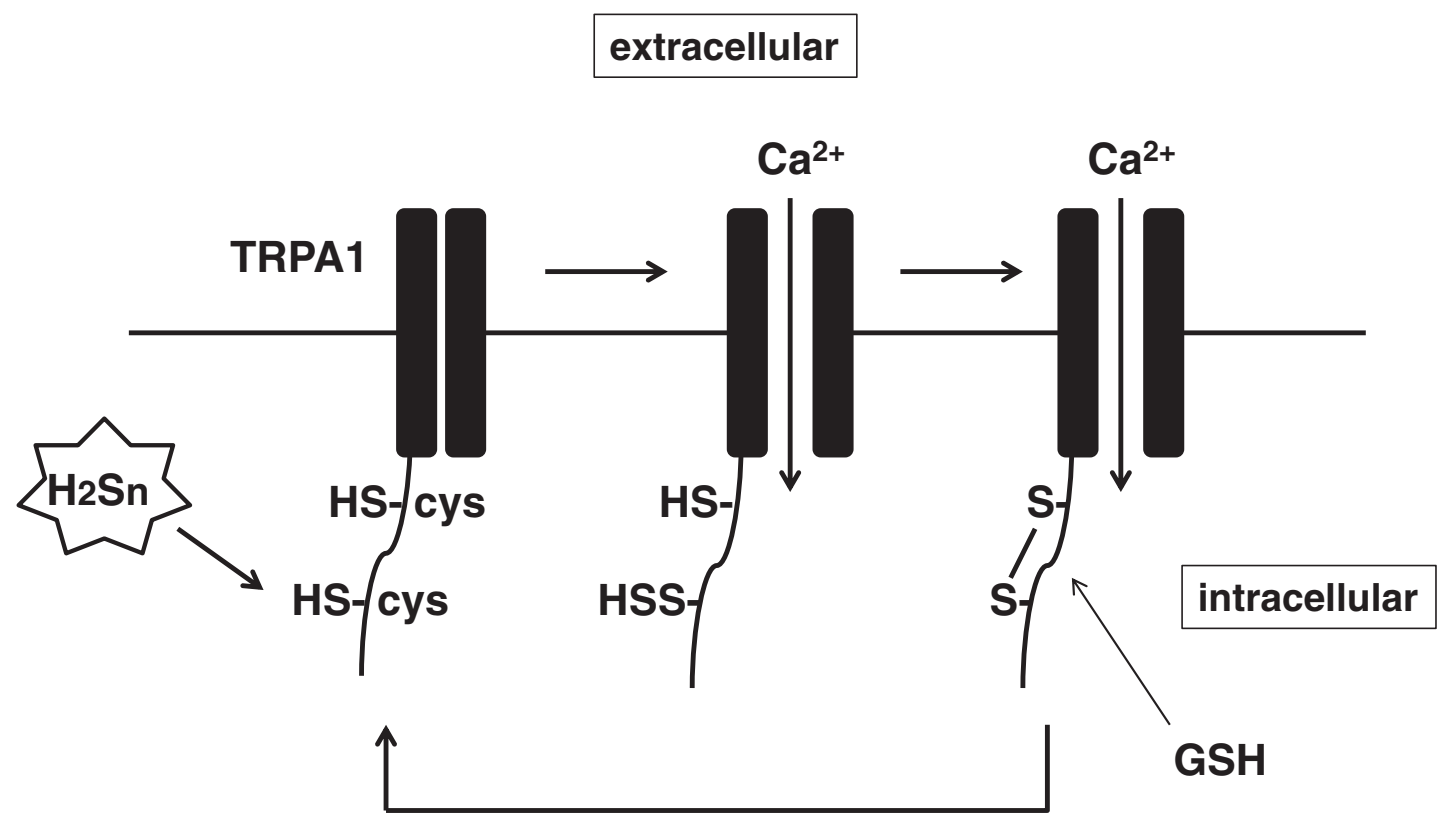

Fig. 11. $\mathrm{H}_{2} \mathrm{~S}_{\mathrm{n}}$ activates TRPA1 channels. TRPA1 channels are activated by $\mathrm{H}_{2} \mathrm{~S}_{\mathrm{n}}$ by sulfurating either one or both of the two cysteine residues at their amino terminus, which then form cysteine disulfide bonds. The conformational changes in TRPA1 channels induce $\mathrm{Ca}^{2+}$ influx.

receptors, but this reaction does not fully explain the mechanism for its facilitation of LTP induction. Shigetomi et al. ${ }^{128)}$ demonstrated that $\mathrm{Ca}^{2+}$ influx through the activated TRPA1 channels facilitates the release of the gliotransmitter D-serine, which enhances the activity of NMDA receptors, in turn leading to the induction of LTP. $\mathrm{H}_{2} \mathrm{~S}_{\mathrm{n}}$ activates TRPA1 channels, whereas $\mathrm{H}_{2} \mathrm{~S}$ activates NMDA receptors by reducing the cysteine disulfide bond. ${ }^{120)}$ The combined activity of $\mathrm{H}_{2} \mathrm{~S}$ and $\mathrm{H}_{2} \mathrm{~S}_{\mathrm{n}}$ facilitates the induction of LTP more efficiently than does DTT, which reduces cysteine disulfide bonds but does not activate TRPA1 channels (Fig. 12).

\section{Modification of protein function by sulfuration}

7.1. Sulfuration (sulfhydration) by $\mathbf{H}_{2}$ S. The modification of enzyme activities through the addition of sulfur to specific cysteine residues of enzymes was studied extensively between the 1960s and 1980s. ${ }^{129)-131)}$ We found that $\mathrm{H}_{2} \mathrm{~S}$ is absorbed and stored in cells as bound sulfane sulfur, which releases $\mathrm{H}_{2} \mathrm{~S}$ in response to reducing agents such as DTT. ${ }^{22)}$ Mustafa et $a .^{21)}$ have defined sulfhydration as a process in which sulfur provided by $\mathrm{H}_{2} \mathrm{~S}$ attaches to reactive cysteine residues in target proteins. Toohey ${ }^{37)}$ has suggested calling it sulfuration, as only sulfur is transferred in the process.
Sulfuration of glyceraldehyde 3-phosphate dehydrogenase (GAPDH) by $\mathrm{H}_{2} \mathrm{~S}$ increases its catalytic activity, and DTT treatment removes the added sulfur to diminish activity. ${ }^{21)}$ This observation is supported by evidence that the GAPDH activity is reduced in CSE knockout mice. Actin polymerization is also enhanced by $\mathrm{H}_{2} \mathrm{~S}$ and reversed by DTT. ${ }^{21)}$ ATP-dependent $\mathrm{K}^{+}$channels, which are involved in vascular smooth muscle relaxation, are activated by sulfuration at cysteine 43 on the Kir6.1 subunit. ${ }^{27)}$ Sulfuration of NF- $\kappa \mathrm{B}$ by $\mathrm{H}_{2} \mathrm{~S}$ facilitates its translocation to the nucleus to up-regulate anti-apoptotic genes, and protein kinase-like ER kinase retains its activity due to the sulfuration of the PTP that regulates ER stress. ${ }^{72), 114)}$ Parkin, an E3 ubiquitin ligase that is suppressed in Parkinson's disease, is also activated by sulfuration. ${ }^{132)}$

Thus, the sulfuration of cysteine residues by $\mathrm{H}_{2} \mathrm{~S}$ seems to play a key role in the regulation of many target proteins. However, it does not. Because atoms with the same oxidation state do not exchange electrons (i.e., do not undergo a redox reaction), the sulfuration of cysteine residues cannot occur (i.e., the oxidation state of sulfur in $\mathrm{H}_{2} \mathrm{~S}$ is -2 , and that in cysteine residues is also -2; Fig. 13). Early studies of sulfuration (sulfhydration) likely measured cysteine residues reacted with $\mathrm{H}_{2} \mathrm{~S}_{\mathrm{n}}$ produced by the oxidation of $\mathrm{H}_{2} \mathrm{~S}$ or the oxidized cysteine residues 


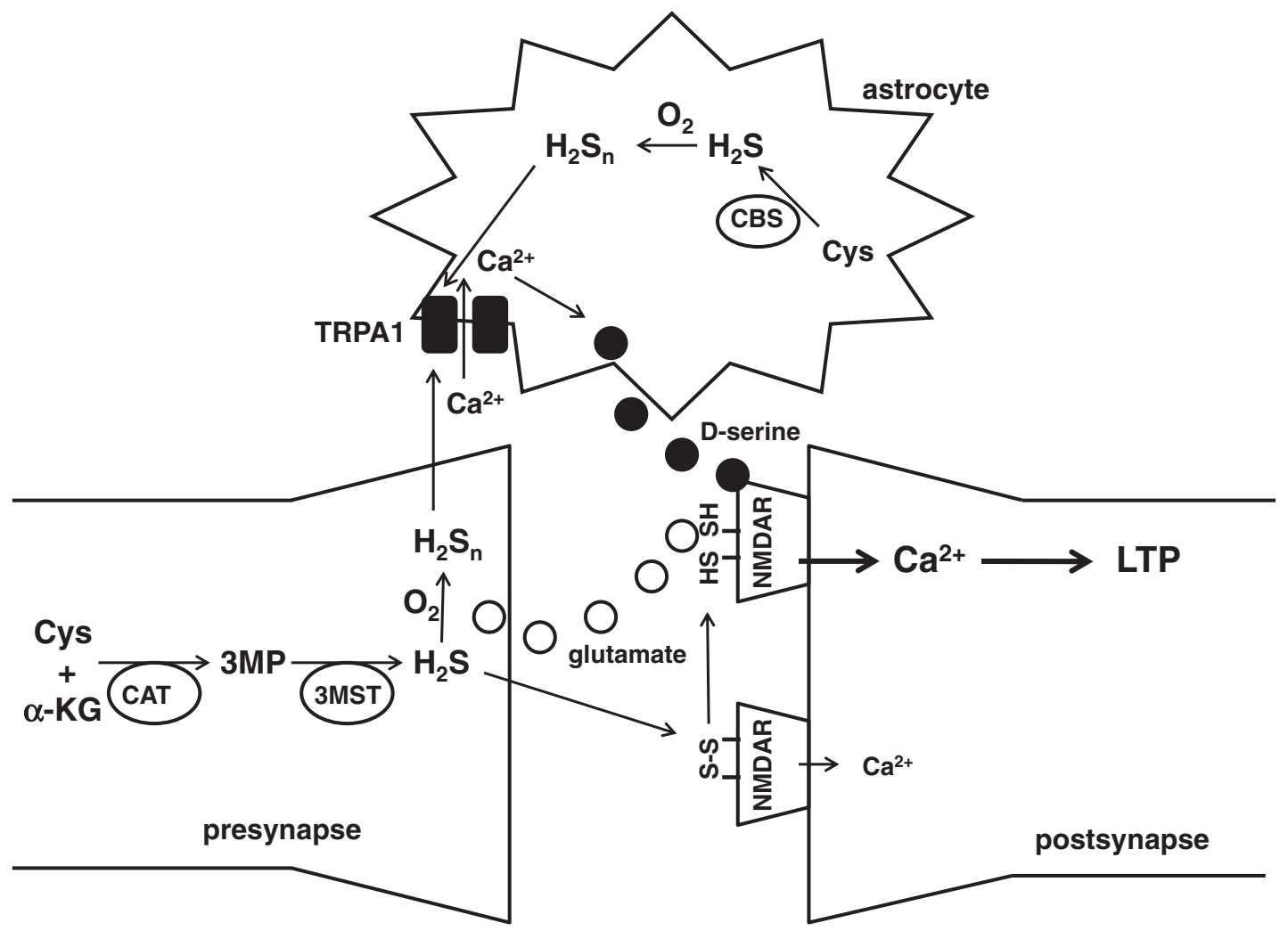

Fig. 12. $\mathrm{H}_{2} \mathrm{~S}$ together with $\mathrm{H}_{2} \mathrm{~S}_{\mathrm{n}}$ facilitates the induction of LTP. $\mathrm{H}_{2} \mathrm{~S}$ enhances the activity of NMDA receptors by reducing a cysteine disulfide bond at the hinge of the ligand-binding domain of the receptors. $\mathrm{H}_{2} \mathrm{~S}_{\mathrm{n}}$ activates TRPA1 channels in astrocytes to induce $\mathrm{Ca}^{2+}$ influx, which facilitates the release of the gliotransmitter, D-serine, to the synaptic cleft. D-serine enhances the activity of NMDA receptors. By these effects of $\mathrm{H}_{2} \mathrm{~S}$ and $\mathrm{H}_{2} \mathrm{~S}_{\mathrm{n}}$ LTP is effectively induced.

reacted with $\mathrm{H}_{2} \mathrm{~S}$ in the same reaction for glutathionylation in which oxidized cysteine residues react with glutathione. ${ }^{50)}$

Tao et al. ${ }^{133)}$ demonstrated that $\mathrm{H}_{2} \mathrm{~S}$ reduces cysteine disulfide bonds but does not sulfurate cysteine residues. $\mathrm{H}_{2} \mathrm{~S}$ induces angiogenesis mediated by vascular endothelial growth factor receptor $2^{134), 135)}$ by reducing a disulfide bond located between cysteine 1045 and cysteine 1024. Mass spectrometry analysis shows that $\mathrm{H}_{2} \mathrm{~S}$ reduces the cysteine disulfide bond contained in the synthesized hexapeptide but does not sulfurate any of the 20 free amino acids, including cysteine. ${ }^{133)}$ The sulfuration of cysteine residues is only transiently observed as an intermediate during the reduction of the disulfide bond, and the intermediate is immediately attacked by a second HS-molecule and reduced to cysteine.

7.2. Sulfuration by $\mathbf{H}_{2} \mathbf{S}_{\mathrm{n}}$. Because the oxidation state of sulfur in $\mathrm{H}_{2} \mathrm{~S}$ and cysteine is -2 , $\mathrm{H}_{2} \mathrm{~S}$ is unable to donate electrons to cysteine. By contrast, $\mathrm{H}_{2} \mathrm{~S}_{\mathrm{n}}$ readily receives electrons from cysteine and transfers sulfur atoms to cysteine. As described in section 6.4, two active cysteine residues at the amino terminus of TRPA1 channels are sulfurated by $\mathrm{H}_{2} \mathrm{~S}_{\mathrm{n}}$ but not by $\mathrm{H}_{2} \mathrm{~S}$.

Another example of the activation of target proteins by sulfuration is Kelch ECH-associating protein 1 (Keap1), which binds to nuclear factor erythroid 2-related factor 2 (Nrf2) to remain in the cytosol. Calvert et al. ${ }^{136)}$ initially reported that $\mathrm{H}_{2} \mathrm{~S}$ facilitates the translocation of Nrf2 to the nucleus, where Nrf2 up-regulates the transcription of antioxidant genes that contribute to the cytoprotective effect of $\mathrm{H}_{2} \mathrm{~S}$. Yang et al. ${ }^{137}$ ) later proposed a mechanism through which $\mathrm{H}_{2} \mathrm{~S}$ sulfurates (sulfhydrates) cysteine residues of Keap1, which releases $\mathrm{Nrf} 2$ to the nucleus. However, $\mathrm{H}_{2} \mathrm{~S}$ does not sulfurate cysteine residues of Keap1 for the reason described earlier. Instead, we showed that $\mathrm{H}_{2} \mathrm{~S}_{4}$ sulfurates Keap1 ${ }^{138)}$ (Fig. 14).

7.3. Other forms of polysulfides. Compared with GSH, glutathione persulfide (GSSH) has greater 


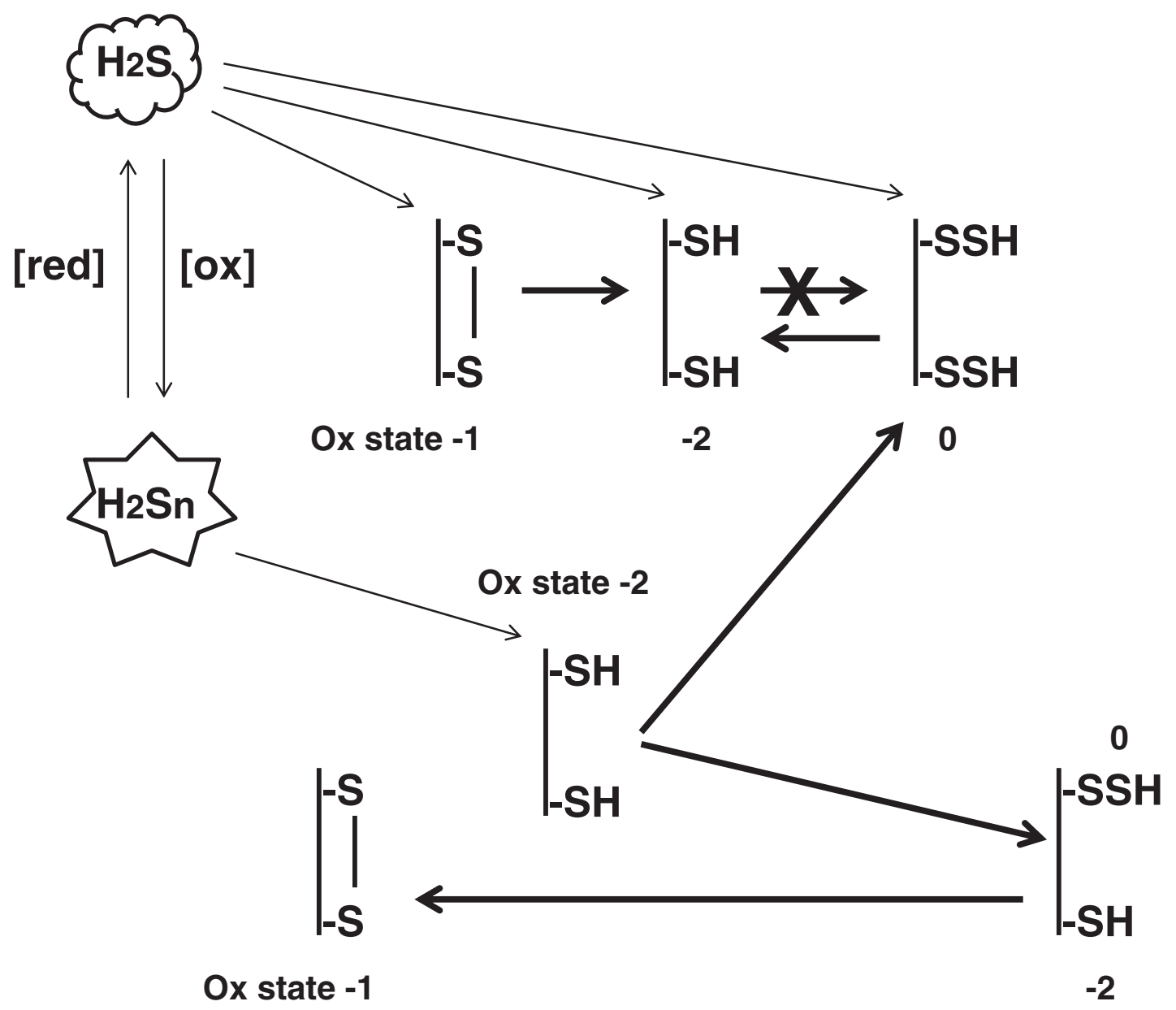

Fig. 13. $\mathrm{H}_{2} \mathrm{~S}$ reduces cysteine disulfide bond while $\mathrm{H}_{2} \mathrm{~S}_{\mathrm{n}}$ sulfurates cysteine residues. The atoms with the same oxidation state are not able to transfer electrons and take part in a redox reaction. $\mathrm{H}_{2} \mathrm{~S}$ reduces sulfur in the cysteine disulfide bond (oxidation state -1 ) and that in persulfide (oxidation state 0 ) to cysteine residues (oxidation state -2 ), while $\mathrm{H}_{2} \mathrm{~S}_{\mathrm{n}}$ (oxidation state 0 ) sulfurates cysteine residues. The resulting persulfide reacts with thiols (oxidation state -2 ) to produce cysteine disulfide bonds.

reducing activity. Massey et al. ${ }^{139)}$ initially reported that GSSH generated from glutathione trisulfide reduces cytochrome c more efficiently than GSH and that cysteine persulfide has similar activity. The effect of GSSH on cytochrome c was confirmed by Fukuto et al. ${ }^{140)}$ who showed a similar reductive effect of GSSH on papain. The reducing activity of GSSH was further confirmed by showing its scavenging effect on $\mathrm{H}_{2} \mathrm{O}_{2} \cdot{ }^{141)}$

CBS and CSE were demonstrated to metabolize cystine rather than cysteine to produce cysteine persulfide, which generates GSSH via an exchange reaction with GSH. ${ }^{141)}$ However, the physiological relevance of this pathway must be re-evaluated. Although CSE has a high affinity for cystine (the extracellular form of cysteine) with a $K_{m}$ value of 30-70 $\mu \mathrm{M}$, CBS and CSE are localized to the cytosol, in which the amount of cystine is insufficient for both enzymes. For instance, only $0.2 \mu \mathrm{M}$ cystine has been measured in the liver, and other tissues contain even lower concentrations. The cell line A549 contains an exceptionally high concentration of cystine at approximately $12 \mu \mathrm{M} .{ }^{141)}$ Even the extracellular concentration of cystine in human blood is only approximately $\left.40 \mu \mathrm{M} .{ }^{142}\right)$ Therefore, it may be difficult for CBS and CSE to produce cysteine persulfide under physiological conditions.

$\mathrm{H}_{2} \mathrm{~S}$ is metabolized by SQR in mitochondria, and GSH receives a sulfur atom from SQR to generate GSSH. ${ }^{55)-57)}$ Libiad et al. ${ }^{143)}$ demonstrated that GSSH can be formed via the enzymatic activity of SQR rather than nonenzymatic sulfane sulfur exchange between cysteine persulfide and oxidized gluthathione reported by Ida et al. ${ }^{141)}$ 


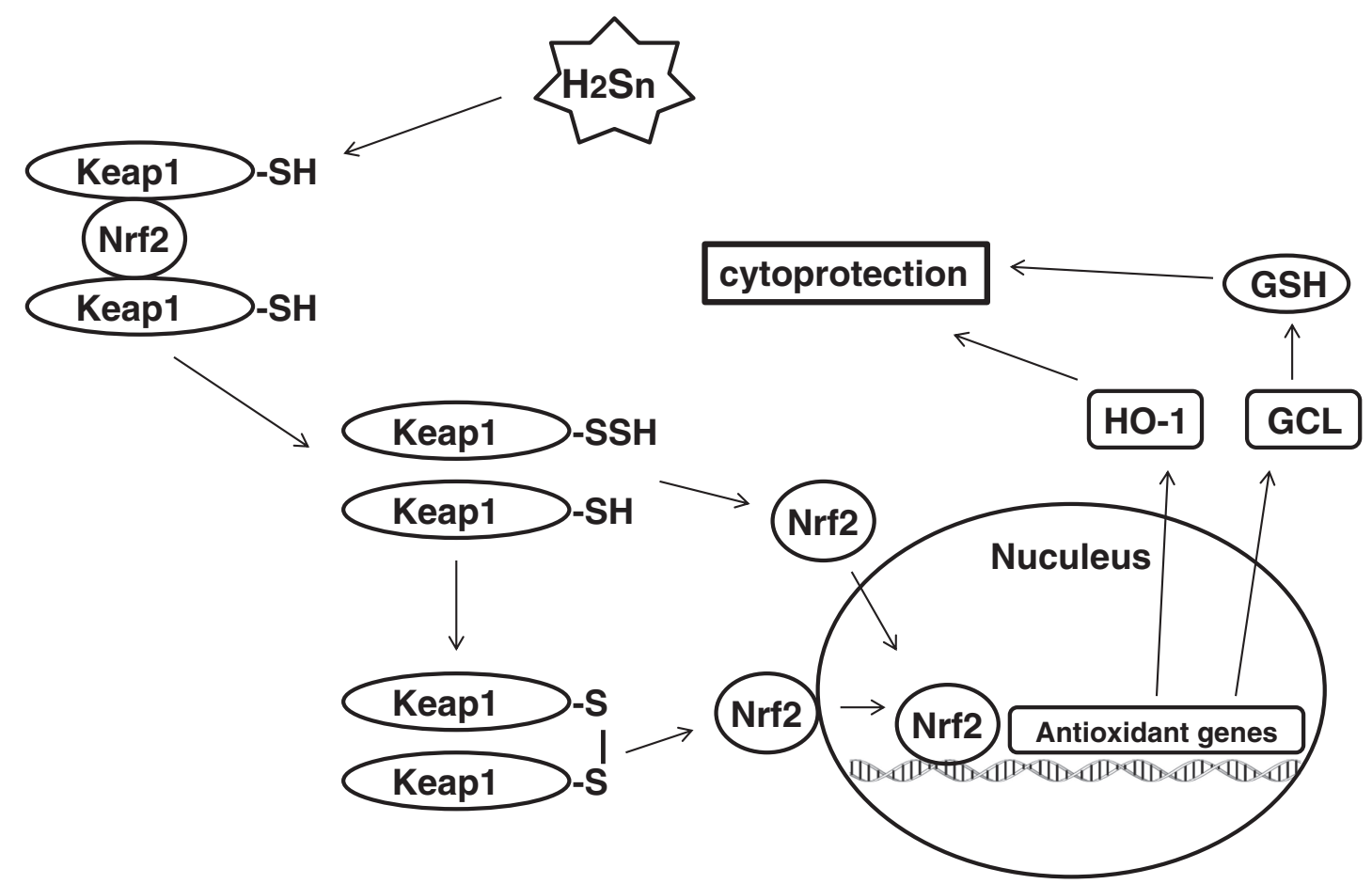

Fig. 14. $\mathrm{H}_{2} \mathrm{~S}_{\mathrm{n}}$ facilitates the nuclear translocation of Nrf2 to up-regulate antioxidant genes. $\mathrm{H}_{2} \mathrm{~S}_{\mathrm{n}}$ sulfurates Keap1 to release Nrf2, which translocates to the nucleus and up-regulates the transcription of antioxidant genes such as heme oxygenase 1 and glutamate cysteine ligase to increase the production of glutathione. By these effects on Keap1/Nrf2 complex, $\mathrm{H}_{2} \mathrm{~S}_{\mathrm{n}}$ exerts its cytoprotective activity.

\section{Cross talk between $\mathrm{H}_{2} \mathrm{~S}$ and $\mathrm{NO}$}

When we discovered the relaxation effect of $\mathrm{H}_{2} \mathrm{~S}$ on smooth muscle, we recognized that this effect was much weaker in the thoracic aorta than in the portal vein and the ileum. In the presence of $\mathrm{NO}$ donors, however, the effect of $\mathrm{H}_{2} \mathrm{~S}$ was greatly augmented and vice versa ${ }^{23)}$ (see Fig. 3 ). This finding was the first demonstration of cross talk between $\mathrm{H}_{2} \mathrm{~S}$ and NO. Moore et al. ${ }^{25), 144)}$ later confirmed the synergistic effect of both molecules in the ileum, and also showed the opposite effect: $\mathrm{H}_{2} \mathrm{~S}$ induces vasoconstriction by scavenging endothelial NO. Zhao et al. ${ }^{26)}$ reported that $\mathrm{H}_{2} \mathrm{~S}$ inhibits the vasorelaxation effect of the NO donor sodium nitroprusside (SNP) and showed that $\mathrm{SNP}$ increases $\mathrm{H}_{2} \mathrm{~S}$ production and another $\mathrm{NO}$ donor, $S$-nitroso- $N$-acetylpenicillamine, up-regulates the expression of CSE. ${ }^{26}$ )

Minamishima et al. ${ }^{145)}$ demonstrated that the protection of cardiomyocytes by $\mathrm{H}_{2} \mathrm{~S}$ is mediated by nitric oxide synthase 3 (eNOS). The application of $\mathrm{Na}_{2} \mathrm{~S}$ increases the phosphorylation of serine 1179 in eNOS to raise serum nitrite and nitrate levels and attenuates cardiac arrest-induced mitochondrial dysfunction. These effects were confirmed when they were not observed in eNOS knockout mice. King et $a l .{ }^{146)}$ performed additional studies on the mediation of $\mathrm{NO}$ in cytoprotection by $\mathrm{H}_{2} \mathrm{~S}$. The eNOS activation site, serine 1179, is less phosphorylated in CSE knockout mice than in wild-type mice, whereas the inhibitory site, threonine 495, is more phosphorylated in CSE knockout mice. ${ }^{146)}$ The application of $\mathrm{Na}_{2} \mathrm{~S}$ activates eNOS to increase the bioavailability of $\mathrm{NO}$ in wild-type mice, but this effect does not occur in eNOS-deficient mice.

$\mathrm{H}_{2} \mathrm{~S}$ induces angiogenesis mediated by vascular endothelial growth factor. ${ }^{134), 135)}$ It also promotes the migration of vascular endothelial cells and facilitates microvessel tube formation. Bir et al. ${ }^{147)}$ demonstrated that the angiogenic effect of $\mathrm{H}_{2} \mathrm{~S}$ is mediated by NO by showing that eNOS knockout mice do not show the effect. By contrast, Szabo et al. ${ }^{148)}$ proposed that the cooperative action between $\mathrm{H}_{2} \mathrm{~S}$ and $\mathrm{NO}$ is essential for angiogenesis by showing that the suppression of the $\mathrm{H}_{2} \mathrm{~S}$-generating enzyme CSE abolishes angiogenesis. The difference in results likely occurred because hypoxic conditions were used in the study by Bir et al. ${ }^{147)}$ whereas Coletta et al. made observations under non-hypoxic conditions. 
The chemical interaction between $\mathrm{H}_{2} \mathrm{~S}$ and $\mathrm{NO}$ produces several potential intermediates. One study showed that nitrosothiol, the chemical structure of which was not reported, is produced from $\mathrm{H}_{2} \mathrm{~S}$ and NO. ${ }^{149)}$ Nitrosothiol does not activate guanylyl cyclase to increase the production of cyclic guanosine monophosphate unless $\mathrm{NO}$ is released with $\mathrm{Cu}^{2+} .{ }^{149}$ ) $\mathrm{H}_{2} \mathrm{~S}$ releases NO from nitrosoglutathione, S-nitroso$\mathrm{N}$-acetylpenicillamine, SNP, and brain homogenates, which may contain nitrosothiols and metal nitrosyl complexes, to relax the vasculature. ${ }^{150)}$ Filipovic et al. ${ }^{151)}$ demonstrated that $\mathrm{H}_{2} \mathrm{~S}$ and nitrite produce the intermediate thionitrous acid, which in turn generates either $\mathrm{NO}$ and the $\mathrm{HS}^{\bullet}$ radical or nitroxyl via further reaction with $\mathrm{H}_{2} \mathrm{~S}$. They also demonstrated that nitroxyl activates TRPA1 channels, which releases calcitonin gene-related peptide, in turn inducing vasodilatation. ${ }^{152)}$ Cortese-Krott et al. ${ }^{153)}$ demonstrated that nitrosopersulfide, which is more stable than thionitrous acid, efficiently releases $\mathrm{NO}$ and $\mathrm{H}_{2} \mathrm{~S}_{\mathrm{n}}$, which results in effective activation of soluble guanylyl cyclase and relaxation of smooth muscle compared to that observed with the parent nitrosothiol

Mustafa et $a .^{21)}$ proposed that the S-nitrosylation of proteins suppresses their activity, whereas sulfuration (sulfhydration) potentiates this activity. Sulfuration of GAPDH increases its catalytic activity, whereas S-nitrosylation of the same cysteine residue abolishes the activity. A similar reciprocal oppositional effect of sulfuration and S-nitrosylation is observed in parkin, in which sulfuration at cysteine 95, a principal site of sulfuration, enhances its activity. Moreover, parkin sulfuration is decreased in the brains of Parkinson's disease patients, in which S-nitrosylation is increased. ${ }^{132)}$ Altaany et al. ${ }^{154)}$ showed that eNOS activity is activated by the sulfuration of cysteine 443, whereas it is suppressed by nitrosylation of this residue. Sulfuration of eNOS decreases S-nitrosylation in eNOS and increases eNOS dimer stability to augment NO bioavailability. Altaany et al. ${ }^{154)}$ also confirmed results published by Minamishima et al. ${ }^{145)}$ and King et al. ${ }^{146)}$ suggesting that NaHS enhances eNOS activity by increasing the phosphorylation of serine 1179 .

\section{Development of $\mathrm{H}_{2} \mathrm{~S}$ - and polysulfide-sensitive fluorescent probes}

The production and clearance of $\mathrm{H}_{2} \mathrm{~S}$ and its absorption by proteins occurs rapidly. Therefore, accurate real-time measurements of the concentration and movement of $\mathrm{H}_{2} \mathrm{~S}$ is difficult. We collaborated with Nagano et al. to develop hydrogen sulfide imaging prove-1 (HSIP-1) a fluorescent probe selective for $\mathrm{H}_{2} \mathrm{~S} .{ }^{155)}$ The probe consists of two functional parts, a site sensitive to $\mathrm{H}_{2} \mathrm{~S}$ and a fluorescence emission fluorophore. HSIP-1 has azamacrocyclic rings that form stable complexes with $\mathrm{Cu}^{2+}$, thereby suppressing the emission of fluorescence. $\mathrm{H}_{2} \mathrm{~S}$ releases $\mathrm{Cu}^{2+}$ from the complex, inducing fluorescence. Because the intracellular concentrations of GSH and cysteine are approximately $1-10 \mathrm{mM}$ and $100 \mu \mathrm{M}$, respectively, whereas that of $\mathrm{H}_{2} \mathrm{~S}$ is below a micromolar order, it is crucial for a probe to detect low concentrations of $\mathrm{H}_{2} \mathrm{~S}$ in the presence of high concentrations of other thiols such as GSH and cysteine. GSH and cysteine do not release $\mathrm{Cu}^{2+}$, which enables HSIP-1 to detect $\mathrm{H}_{2} \mathrm{~S}$ selectively with almost no response to $10 \mathrm{mM}$ GSH and $1 \mathrm{mM}$ cysteine. The fluorescence intensity is increased 50 -fold in $5 \mathrm{~min}$ in the presence of $10 \mu \mathrm{M} \mathrm{H}_{2} \mathrm{~S}$.

Several other probes were reported in 2011. The sensitivity of SF1, SF2, and DNS-Az to $\mathrm{H}_{2} \mathrm{~S}$ is based on the reduction of azides to amines by $\mathrm{H}_{2} \mathrm{~S}$ that triggers changes in the electronic properties of a fluorophore, which then emits fluorescence. ${ }^{156), 157)}$ The fluorophore of SF1 and SF2 is rhodamine, and that of DNS-Az is a dansyl group. Within $1 \mathrm{~h}$ of $\mathrm{H}_{2} \mathrm{~S}$ exposure, SF1 and SF2 showed increases in fluorescence intensity of 7 - and 9-fold, respectively. The detection limit for $\mathrm{SF} 1$ and $\mathrm{SF} 2$ is $5-10 \mu \mathrm{M} \mathrm{H} \mathrm{H}_{2} \mathrm{~S}$. The response of DNS-Az is fast, reaching a peak within $10 \mathrm{~s}$ and showing a 40-fold increase in fluorescence intensity in the presence of $25 \mu \mathrm{M} \mathrm{H}_{2} \mathrm{~S}$.

SFP-1, SFP-2, and Probe 1 have similar $\mathrm{H}_{2} \mathrm{~S}$ binding sites at which $\mathrm{H}_{2} \mathrm{~S}$ reacts with an electrophilic component to form a free $\mathrm{SH}$-containing intermediate, which then reacts with an ester group at the suitable position for cyclization. Upon cyclization, the fluorophores emit fluorescence. ${ }^{158), 159)}$ The fluorescence intensity of Probe 1 increases by 55to 70 -fold in the presence of $50 \mu \mathrm{M} \mathrm{H} \mathrm{H}_{2} \mathrm{~S}$ after $1 \mathrm{~h}$, whereas that of SFP-1 and SFP-2 increase by 13 -fold under the same conditions.

Because $\mathrm{H}_{2} \mathrm{~S}_{\mathrm{n}}$ species have recently been identified as a $\mathrm{H}_{2} \mathrm{~S}$-related signaling molecule, the polysulfide-sensitive fluorescence probes SSP1 and SSP2 have been developed. ${ }^{160)}$ The $\mathrm{SH}$ group of the probes acts as a nucleophile to trap the reactive sulfur atoms of polysulfides. The resultant intermediates, -SSH adducts, undergo a fast intramolecular cyclization to release the fluorophore. SSP1 and SSP2 are selective to sulfane sulfur species and do not react with other biologically relevant sulfur species such as cysteine and GSH. 
The sensitivity and response times of these probes must be improved. Furthermore, the responses of these probes to $\mathrm{H}_{2} \mathrm{~S}$ and sulfane sulfur are irreversible, and the development of more desirable reversible probes is awaited.

\section{Other roles of $\mathrm{H}_{2} \mathrm{~S}$ and therapeutic applications}

Since the identification of the neuromodulation, vascular relaxation, and cytoprotection roles of $\mathrm{H}_{2} \mathrm{~S}$, various other roles have been identified, such as those in the regulation of inflammation, reduction of insulin release, suppression of cancer growth, and detection of cellular oxygen levels. ${ }^{161)-165)} \mathrm{H}_{2} \mathrm{~S}$ regulates inflammatory processes and their resolution. A significant anti-inflammatory effect was initially reported by Zanardo et al., ${ }^{163)}$ who showed that $\mathrm{H}_{2} \mathrm{~S}$ inhibits leukocyte adherence to the vascular endothelium as well as accumulation and edema formation. The discovery of these beneficial effects spurred the development of several $\mathrm{H}_{2} \mathrm{~S}$ donors and $\mathrm{H}_{2} \mathrm{~S}$-releasing non-steroidal anti-inflammatory drugs with no significant side effects in the gastrointestinal tract. ${ }^{166)}$ Many of these drugs have shown considerable promise in relevant animal models and are presently undergoing clinical trials.

$\mathrm{H}_{2} \mathrm{~S}$ inhibits cancer development, induces cell cycle arrest in the $\mathrm{G} 2 / \mathrm{M}$ phase, and promotes apoptosis. ${ }^{167)} \mathrm{H}_{2}$ S-releasing non-steroidal anti-inflammatory drugs enhance these chemopreventive effects on cancer cells, and so-called NOSH compounds, which release both $\mathrm{H}_{2} \mathrm{~S}$ and $\mathrm{NO}$, have been developed to suppress cancer growth. ${ }^{164), 168)}$ Contrary to these observations, CBS expression is up-regulated in colorectal and ovarian cancer cells, in which $\mathrm{H}_{2} \mathrm{~S}$ is involved in promoting cellular growth and migration. ${ }^{169)}$ In these cells, suppression of CBS activity may be a potential therapy.

It is important to detect concentrations of $\mathrm{O}_{2}$ in the blood and respond to hypoxia by dilating blood vessels to increase blood flow. $\mathrm{O}_{2}$ levels are also relayed to the brainstem to increase breathing and cardiovascular function. Olson et al. ${ }^{165), 170)}$ demonstrated that the $\mathrm{O}_{2}$-dependent metabolism of $\mathrm{H}_{2} \mathrm{~S}$ may be an effective $\mathrm{O}_{2}$-sensing mechanism. Tissue $\mathrm{H}_{2} \mathrm{~S}$ concentrations are inversely related to $\mathrm{O}_{2}$ concentrations, and this reciprocal relationship is responsible for a similar effect between hypoxia and $\mathrm{H}_{2} \mathrm{~S} . \mathrm{H}_{2} \mathrm{~S}$ production is closely linked to cellular oxidative states. ${ }^{50), 171)}$ Oxidative stress depletes GSH and cysteine, which in turn enhances the activity of CBS to stimulate the production of $\mathrm{H}_{2} \mathrm{~S}$, cysteine, and GSH, which protect cells from oxidative stress. ${ }^{50)}$

\section{Concluding remarks}

Two decades ago, what was considered merely a pungent gas was found to be a physiological mediator of cognitive function and vascular tone. Since then, numerous physiological roles for $\mathrm{H}_{2} \mathrm{~S}$ - such as protecting various tissues and organs from ischemic insults or oxidative stress, a universal defense mechanism across a diverse spectrum of species; regulating inflammation; inducing angiogenesis; and oxygen sensing - have been confirmed. Recently identified $\mathrm{H}_{2} \mathrm{~S}_{\mathrm{n}}$ species are considerably potent and induce various physiological responses, some of which were previously ascribed to $\mathrm{H}_{2} \mathrm{~S}$. The cross talk between $\mathrm{H}_{2} \mathrm{~S}$ and $\mathrm{NO}$, which was initially demonstrated as a synergistic interaction of both molecules, led to the identification of $\mathrm{H}_{2} \mathrm{~S}$ regulation on $\mathrm{NO}$ bioavailability and the generation of several potential signaling molecules from both compounds. Understanding of the biochemical nature of these molecules as well as their mechanisms of action, will elucidate the physiological roles and therapeutic potential of $\mathrm{H}_{2} \mathrm{~S}$ and related molecules.

\section{Acknowledgements}

I would like to thank Professor David Schubert for encouraging and supporting H.K. to promote the study of hydrogen sulfide. I thank all colleagues during their stay in our labs for their contribution to the study: Drs. Kazuho Abe, Norihiro Shibuya, Isao Ishii, Yasushi Enokido, Yasuo Nagai, Ken Umemura, Yoshinori Mikami, Kazuhiko Namekata, Mamiko Tsugane, Mari Ishigami, Shin Koike, Noriyuki Akahoshi, Yuriko Kobayashi, Makiko Tanaka, and Yuka Kimura. I also thank Professors. Norio Matsuki, Makoto Suematsu, Yuki Ogasawara, Sachio Takashima, Noriyuki Nagahara, David Lefer, Kazuyuki Ishii, Tetsuo Nagano, Kenjiro Hanaoka, Toshihide Kimura, Yukiko Kaneko, Rumiko Hosoki, Akiko Ichinohe, Takeshi Kanaumi, and late Prof. Ichiro Niki for their collaboration.

This work is supported by a grant from National Institute of Neuroscience and KAKENHI (26460115) Grant-in-Aid for Scientific Research to H.K.

\section{References}

1) Furchgott, R.F. and Zawadzki, J.V. (1980) The obligatory role of endothelial cells in the relaxation of arterial smooth muscle by acetylcholine. Nature 288, 373-376. 
2) Furchgott, R.F. (1988) Studies on relaxation of rabbit aorta by sodium nitrate: basis for the proposal that the acid-activatable component of the inhibitory factor from retractor penis is inorganic nitrate and the endothelium-derived relaxing factor is nitric oxide. In Mechanisms of Vasodilatation (ed. Vanhoutte, P.M.). Raven, New York, pp. 401-414.

3) Ignarro, L.J., Byrns, R.E. and Wood, K.S. (1988) Biochemical and pharmacological properties of endothelium-derived relaxing factor and its similarity to nitric oxide radical. In Mechanisms of Vasodilatation (ed. Vanhoutte, P.M.). Raven, New York, pp. 427-435.

4) Garthwaite, J., Charles, S.L. and Chess-Williams, R. (1988) Endothelium-derived relaxing factor release on activation of NMDA receptors suggests role as intercellular messenger in the brain. Nature 336, 385-388.

5) O'Dell, T.J., Hawkins, R.D., Kandel, E.R. and Arancio, O. (1991) Tests of the roles of two diffusible substances in long-term potentiation: evidence for nitric oxide as a possible early retrograde messenger. Proc. Natl. Acad. Sci. U.S.A. 88, 11285-11289.

6) Verma, A., Hirsch, D.J., Glatt, E.E., Ronnett, G.V. and Snyder, S.H. (1993) Carbon monoxide: a putative neural messenger. Science 259, 381-384.

7) Stevens, C.F. and Wang, Y. (1993) Reversal of longterm potentiation by inhibitors of haem oxygenase. Nature 364, 147-149.

8) Zhuo, M., Small, S.A., Kandel, E.R. and Hawkins, R.D. (1993) Nitric oxide and carbon monoxide produce activity-dependent long-term synaptic enhancement in hippocampus. Science $\mathbf{2 6 0}$, 1946-1950.

9) Ramazzini, B. (1713) Diseases of Workers. (Translated from the Latin text De Morbis Artificum by W.C. Wright, 1940) History Med. Vol. 23, Univ. Chicago Press, Chicago.

10) Reiffenstein, J.J., Hulbert, W.C. and Roth, S.H. (1992) Toxicology of hydrogen sulfide. Annu. Rev. Pharmacol. Toxicol. 32, 109-134.

11) Kombian, S.B., Warenycia, M.W., Mele, F.G. and Reiffenstein, R.J. (1988) Effects of acute intoxication with hydrogen sulfide on central amino acid transmitter systems. Neurotoxicol. 9, 587596.

12) Kombian, S.B., Reiffenstein, R.J. and Colmers, W.F. (1993) The actions of hydrogen sulfide on dorsal raphe serotonergic neurons in vitro. J. Neurophysiol. 70, 81-96.

13) Warenycia, M.W., Goodwin, L.R., Benishin, C.G., Reiffenstein, R.J., Grancom, D.M., Taylor, J.D. and Dieken, F.P. (1989) Acute hydrogen sulfide poisoning. Demonstration of selective uptake of sulfide by the brainstem by measurement of brain sulfide levels. Biochem. Pharmacol. 38, 973-981.

14) Goodwin, L.R., Francom, D., Dieken, F.P., Taylor, J.D., Warenycia, M.W., Reiffenstein, R.J. and Dowling, G. (1989) Determination of sulfide in brain tissue by gas dialysis/ion chromatography: postmortem studies and two case reports. J. Anal. Toxicol. 13, 105-109.

15) Meister, A., Fraser, P.E. and Tice, S.V. (1954) Enzymatic desulfuration of $\beta$-mercaptopyruvate to pyruvate. J. Biol. Chem. 206, 561-575.

16) Cavallini, D., Mondovi, B., De Marco, C. and Scioscia-Santoro, A. (1962) The mechanism of desulphhydration of cysteine. Enzymologia 24, 253-266.

17) Braunstein, A.E., Goryachenkowa, E.V., Tolosa, E.A., Willhardt, I.H. and Yefremova, L.L. (1971) Specificity and some other properties of liver serine sulphhydrase: evidence for its identity with cystathionine $\beta$-synthase. Biochim. Biophys. Acta 242, 247-260.

18) Stipanuk, M.H. and Beck, P.W. (1982) Characterization of the enzymic capacity for cysteine desulphhydration in liver and kidney of the rat. Biochem. J. 206, 267-277.

19) Abe, K. and Kimura, H. (1996) The possible role of hydrogen sulfide as an endogenous neuromodulator. J. Neurosci. 16, 1066-1071.

20) Travis, J. (1996) The rotten smell of memory: It's a gas. Sci. News 149, 116.

21) Mustafa, A.K., Gadalla, M.M., Sen, N., Kim, S. $\mathrm{Mu}$, W., Gazi, S.K., Barrow, R.K., Yang, G., Wang, R. and Snyder, S.H. (2009) $\mathrm{H}_{2} \mathrm{~S}$ signals through protein S-sulfhydration. Sci. Signal. 2, ra72.

22) Ishigami, M., Hiraki, K., Umemura, K., Ogasawara, Y., Ishii, K. and Kimura, H. (2009) A source of hydrogen sulfide and a mechanism of its release in the brain. Antioxid. Redox Signal. 11, 205-214.

23) Hosoki, R., Matsuki, N. and Kimura, H. (1997) The possible role of hydrogen sulfide as an endogenous smooth muscle relaxant in synergy with nitric oxide. Biochem. Biophys. Res. Commun. 237, 527-531.

24) Bredt, D.A. and Snyder, S.H. (1990) Isolation of nitric oxide synthetase, a calmodulin-requiring enzyme. Proc. Natl. Acad. Sci. U.S.A. 87, 682685 .

25) Teague, B., Asiedu, S. and Moore, P.K. (2002) The smooth muscle relaxant effect of hydrogen sulphide in vitro: Evidence for a physiological role to control intestinal contractility. Br. J. Pharmacol. 137, 139-145.

26) Zhao, W., Zhang, J., Lu, Y. and Wang, R. (2001) The vasorelaxant effect of $\mathrm{H}_{2} \mathrm{~S}$ as a novel endogenous gaseous $\mathrm{K}_{\mathrm{ATP}}$ channel opener. EMBO J. 20, 6008-6016.

27) Mustafa, A.K., Sikka, G., Gazi, S.K., Steppan, J., Jung, S.M., Bhunia, A.K., Barodka, V.M., Gazi, F.K., Barrow, R.K., Wang, R., Amzel, L.M., Berkowitz, D.E. and Snyder, S.H. (2011) Hydrogen sulfide as endothelium-derived hyperpolarizing factor sulfhydrates potassium channels. Circ. Res. 109, 1259-1268.

28) Meyer, B., Ward, K., Koshlap, K. and Peter, L. (1983) Second dissociation constant of hydrogen sulfide. Inorg. Chem. 22, 2345-2346.

29) Casey, J.R., Grinstein, S. and Orlowski, J. (2010) 
Sensors and regulators of intracellular pH. Nat. Rev. Mol. Cell Biol. 11, 50-61.

30) Mathai, J.C., Missner, A., Kugler, P., Saparov, S.M., Zeidel, M.L., Lee, J.K. and Pohl, P. (2009) No facilitator required for membrane transport of hydrogen sulfide. Proc. Natl. Acad. Sci. U.S.A. 106, 16633-16638.

31) Cuevasanta, E., Denicola, A., Alvarez, B. and Moller, M.N. (2012) Solubility and permeation of hydrogen sulfide in lipid membranes. PLoS ONE 7, e34562.

32) Jennings, M.L. (2013) Transport of $\mathrm{H}_{2} \mathrm{~S}$ and $\mathrm{HS}^{-}$ across the human red blood cell membrane: rapid $\mathrm{H}_{2} \mathrm{~S}$ diffusion and AE1-mediated $\mathrm{Cl}^{-} / \mathrm{HS}^{-}$exchange. Am. J. Physiol. Cell Physiol. 305, C941C950.

33) Czyzewski, B.K. and Wang, D.-N. (2012) Identification and characterization of a bacterial hydrosulphide ion channel. Nature 483, 494-497.

34) Furne, J., Saeed, A. and Levitt, M.D. (2008) Whole tissue hydrogen sulfide concentrations are orders of magnitude lower than presently accepted values. Am. J. Physiol. Regul. Integr. Comp. Physiol. 295, R1479-R1498.

35) Wintner, E.A., Deckwerth, T.L., Langston, W., Bengtsson, A., Leviten, D., Hill, P., Insko, M.A., Dumpit, R., VandenEkart, E., Toombs, C.F. and Szabo, C. (2010) A monobromobimane-based assay to measure the pharmacokinetic profile of reactive sulphide species in blood. Br. J. Pharmacol. 160, 941-957.

36) Ogasawara, Y., Isoda, S. and Tanabe, S. (1994) Tissue and subcellular distribution of bound and acid-labile sulfur, and the enzymic capacity for sulfide production in the rat. Biol. Pharm. Bull. 17, 1535-1542.

37) Toohey, J.I. (2011) Sulfur signaling: Is the agent sulfide or sulfane? Anal. Biochem. 413, 1-7.

38) Shibuya, N., Tanaka, M., Yoshida, M., Ogasawara, Y., Togawa, T., Ishii, K. and Kimura, H. (2009) 3-Mercaptopyruvate sulfurtransferease produces hydrogen sulfide and bound sulfane sulfur in the brain. Antioxid. Redox Signal. 11, 703-714.

39) Mikami, Y., Shibuya, N., Kimura, Y., Nagahara, N., Ogasawara, Y. and Kimura, H. (2011) Thioredoxin and dihydrolipoic acid are required for 3mercaptopyruvate sulfurtransferase to produce hydrogen sulfide. Biochem. J. 439, 479-485.

40) Brookes, N. and Turner, R.J. (1994) $\mathrm{K}^{+}$-induced alkalinization in mouse cerebral astrocytes mediated by reversal of electrogenic $\mathrm{Na}^{+}-\mathrm{HCO}_{3}{ }^{-}$ cotransport. Am. J. Physiol. 267, C1633-C1640.

41) Levitt, M.D., Abdel-Rehim, M.S. and Furne, J. (2011) Free and acid-labile hydrogen sulfide concentrations in mouse tissues: Anomalously high free hydrogen sulfide in aortic tissue. Antioxid. Redox Signal. 15, 373-378.

42) Whitfield, N.L., Kreimier, E.L., Verdial, F.C., Skovgaard, N. and Olson, K.R. (2008) Reappraisal of $\mathrm{H}_{2} \mathrm{~S}$ /sulfide concentration in vertebrate blood and its potential significance in ischemic preconditioning and vascular signaling. Am. J.
Physiol. Regul. Integr. Comp. Physiol. 294, R1930-R1937.

43) Shen, X., Pattillo, C.B., Pardue, S., Bir, S.C., Wang, R. and Kevil, C.G. (2011) Measurement of plasma hydrogen sulfide in vivo and in vitro. Free Radic. Biol. Med. 50, 1021-1031.

44) Shen, X., Peter, E.A., Bir, S., Wang, R. and Kevil, C.G. (2012) Analytical measurement of discrete hydrogen sulfide pools in biological specimens. Free Radic. Biol. Med. 52, 2276-2283.

45) Nagai, Y., Tsugane, M., Oka, J. and Kimura, H. (2004) Hydrogen sulfide induces calcium waves in astrocytes. FASEB J. 18, 557-559.

46) Chen, X., Jhee, K.H. and Kruger, W.D. (2004) Production of the neuromodulator $\mathrm{H}_{2} \mathrm{~S}$ by cystathionine beta-synthase via the condensation of cysteine and homocystein. J. Biol. Chem. 279, 52082-52086.

47) Singh, S., Padovani, D., Leslie, R.A., Chiku, T. and Banerjee, R. (2009) Relative contributions of cystathionine beta-synthase and gamma-cystathionase to $\mathrm{H}_{2} \mathrm{~S}$ biogenesis via alternative transsulfuration reactions. J. Biol. Chem. 284, 2245722466.

48) Finkelstein, J.D., Kyle, W.E., Martin, J.J. and Pick, A.M. (1975) Activation of cystathionine synthase by adenosylmethionine and adenosylethionine. Biochem. Biophys. Res. Commun. 66, 81-87.

49) Shan, X., Dunbrack, R.L.J., Christopher, S.A. and Kruger, W.D. (2001) Mutation in the regulatory domain of cystathionine $\beta$-synthase can functionally suppress patient-derived mutations in cis. Hum. Mol. Genet. 10, 635-643.

50) Niu, W.-N., Yadav, P.K., Adame, J. and Banerjee, R. (2015) S-Glutathionylation enhances human cystathionine $\beta$-synthase activity under oxidative stress conditions. Antioxid. Redox Signal. 22, 350-361.

51) Taoka, S. and Banerjee, R. (2001) Characterization of NO binding to human cystathionine betasynthase: Possible implications of the effects of $\mathrm{CO}$ and NO binding to the human enzyme. J. Inorg. Biochem. 87, 245-251.

52) Morikawa, T., Kajimura, M., Nakamura, T., Hishiki, T., Nakanishi, T., Yukutake, Y., Nagahata, Y., Ishikawa, M., Hattori, K., Takenouchi, T., Takahashi, T., Ishii, I., Matsubara, K., Kabe, Y., Uchiyama, S., Nagata, E., Gadalla, M.M., Snyder, S.H. and Suematsu, M. (2012) Hypoxic regulation of the cerebral microcirculation is mediated by a carbon monoxide-sensitive hydrogen sulfide pathway. Proc. Natl. Acad. Sci. U.S.A. 109, 1293-1298.

53) Kimura, H. (2012) Metabolic turnover of hydrogen sulfide. Front. Physiol. 3, Article 101, 1-3.

54) Vitvitsky, V., Kabil, O. and Banerjee, R. (2012) High turnover rates for hydrogen sulfide allow for rapid regulation of its tissue concentrations. Antioxid. Redox Signal. 17, 22-31.

55) Hildebrandt, T.M. and Grieshaber, M.K. (2008) Three enzymatic activities catalyze the oxidation of sulfide to thiosulfate in mammalian and 
invertebrate mitochondria. FEBS J. 275, 33523361.

56) Tiranti, V., Viscomi, C., Hildebrandt, T., Meo, I.D., Mineri, R., Tiveron, C., Levitt, M.D., Prelle, A., Fagiolari, G., Rimoldi, M. and Zeviani, M. (2009) Loss of ETHE1, a mitochondrial dioxygenase, causes fatal sulfide toxicity in ethylmalonic encephalopathy. Nat. Med. 15, 200-205.

57) Viscomi, C., Burlina, A.B., Dweikat, I., Savoiardo, M., Lamperti, C., Hildebrandt, T., Tiranti, V. and Zeviani, M. (2010) Combined treatment with oral metaronidazole and $\mathrm{N}$-acetylcysteine is effective in ethylmalonic encephalopathy. Nat. Med. 16. 869-871.

58) Enokido, Y., Suzuki, E., Iwasawa, K., Namekata, K., Okazawa, H. and Kimura, H. (2005) Cystathionine beta-synthase, a key enzyme for homocysteine metabolism, is preferentially expressed in the radial glia/astrocyte lineage of developing mouse CNS. FASEB J. 19, 1854-1856.

59) Ichinohe, A., Kanaumi, T., Takashima, S., Enokido, Y., Nagai, Y. and Kimura, H. (2005) Cystathionine beta-synthase is enriched in the brains of Down's patients. Biochem. Biophys. Res. Commun. 338, 1547-1550.

60) Namekata, K., Enokido, Y., Ishii, I., Nagai, Y., Harada, T. and Kimura, H. (2004) Abnormal lipid metabolism in cystathionine $\beta$-synthase-deficient mice, an animal model for hyperhomocysteinemia. J. Biol. Chem. 279, 52961-52969.

61) Robert, K., Vialard, F., Thiery, E., Toyama, K. Sinet, P.M., Janel, N. and London, J. (2003) Expression of the cystathionine beta synthase (CBS) gene during mouse development and immunolocalization in adult brain. J. Histochem. Cytochem. 51, 363-371.

62) Barbaux, S., Plomin, R. and Whitehead, A.S. (2000) Polymorphisms of genes controlling homocysteine/folate metabolism and cognitive function. Neuroreport 11, 1133-1136.

63) Chiku, T., Padovani, D., Zhu, W., Singh, S., Vitvitsky, V. and Banerjee, R. (2009) $\mathrm{H}_{2} \mathrm{~S}$ biogenesis by human cystathionine $\gamma$-lyase leads to the novel sulfur metabolites lanthionine and homolanthionine and is responsive to the grade of hyperhomocysteinemia. J. Biol. Chem. 284, 11601-11612.

64) Sun, Q., Collins, R., Huang, S., HolmbergSchiavone, L., Anand, G.S., Tan, C.H., van-denBerg, S., Deng, L.W., Moore, P.K., Karlberg, T. and Sivaraman, J. (2009) Structural basis for the inhibition mechanism of human cystathionine gamma-lyase, an enzyme responsible for the production of $\mathrm{H}_{2} \mathrm{~S}$. J. Biol. Chem. 284, 30763085 .

65) Yang, G., Wu, L., Jiang, B., Yang, W., Qi, J., Cao, K., Meng, Q., Mustafa, A.K., Mu, W., Zhang, S., Snyder, S.H. and Wang, R. (2008) $\mathrm{H}_{2} \mathrm{~S}$ as a physiologic vasorelaxant: Hypertension in mice with deletion of cystathionine $\gamma$-lyase. Science 322, 587-590

66) Mikami, Y., Shibuya, N., Ogasawara, Y. and
Kimura, H. (2013) Hydrogen sulfide is produced by cystathionine $\gamma$-lyase at the steady-state low intracellular $\mathrm{Ca}^{2+}$ concentrations. Biochem. Biophys. Res. Commun. 431, 131-135.

67) Shibuya, N., Mikami, Y., Kimura, Y., Nagahara, N. and Kimura, H. (2009) Vascular endothelium exresses 3-mercaptopyruvate sulfurtransferase and produces hydrogen sulfide. J. Biochem. 146, 623-626.

68) Olson, K.R., Whitfield, N.L., Bearden, S.E., Leger, J.S., Nilson, E., Gao, Y. and Maddeen, J.A. (2010) Hypoxic pulmonary vasodilation: a paradigm shift with a hydrogen sulfide mechanism. Am. J. Physiol. Regul. Integr. Comp. Physiol. 298, R51-R60.

69) Ishii, I., Akahoshi, N., Yamada, H., Nakano, S., Izumi, T. and Suematsu, M. (2010) Cystathionine $\gamma$-lyase-deficient mice require dietary cysteine to protect against acute lethal myopathy and oxidative injury. J. Biol. Chem. 285, 26358-26368.

70) Ishii, I., Akahoshi, N., Yu, X.-N., Kobayashi, Y., Namekata, K., Komaki, G. and Kimura, H. (2004) Murine cystathionine $\gamma$-lyase: complete cDNA and genomic sequences, promoter activity, tissue distribution and developmental expression. Biochem. J. 381, 113-123.

71) Yang, G., Pei, Y., Teng, H., Cao, Q. and Wang, R. (2011) Specificity protein-1 as a critical regulator of human cystathionine $\gamma$-lyase in smooth muscle cells. J. Biol. Chem. 286, 26450-26460.

72) Sen, N., Paul, B.D., Gadalla, M.M., Mustafa, A.K., Sen, T., Xu, R., Kim, S. and Snyder, S.H. (2012) Hydrogen sulfide-linked sulfhydration of NF- $\kappa \mathrm{B}$ mediates its antiapoptotic actions. Mol. Cell 45, $13-24$.

73) Kabil, O., Vitvitsky, V., Xie, P. and Banerjee, R. (2011) The quantitative significance of the transsulfuration enzymes for $\mathrm{H}_{2} \mathrm{~S}$ production in murine tissues. Antioxid. Redox Signal. 15, 363-372.

74) Paul, B.D., Sbodio, J.I., Xu, R., Vandiver, M.S., Cha, J.Y., Snowman, A.M. and Snyder, S.H. (2014) Cystathionine $\gamma$-lyase deficiency mediates neurodegeneration in Huntington's disease. Nature 509, 96-100.

75) Cooper, A.J.L. (1983) Biochemistry of sulfur-containing amino acids. Annu. Rev. Biochem. 52, $187-222$.

76) Ubuka, T., Hosaki, Y., Nishina, H. and Ikeda, T. (1985) 3-Mercaptopyruvate sulfurtransferase activity in guinea pig and rat tissues. Physiol. Chem. Phys. Med. NMR 17, 41-43.

77) Wrobel, M., Wlodek, L. and Srebro, Z. (1996) Sulfurtransferases activity and the level of lowmolecular-weight thiols and sulfane sulfur compounds in cortex and brain stem of mouse. Neurobiology (Bp.) 4, 217-222.

78) Shibuya, N., Koike, S., Tanaka, M., Ishigami-Yuasa, M., Kimura, Y., Ogasawara, Y., Fukui, K., Nagahara, N. and Kimura, H. (2013) A novel pathway for the production of hydrogen sulfide from D-cysteine in mammalian cells. Nat. Commun. 4, 1366. 
79) Nagahara, N., Ito, T., Kitamura, H. and Nishino, T. (1998) Tissue and subcellular distribution of mercaptopyruvate sulfurtransferase in the rat: confocal laser fluorescence and immunoelectron microscopic studies combined with biochemical analysis. Histochem. Cell Biol. 110, 243-250.

80) Griffith, O.W. (1999) Biologic and pharmacologic regulation of mammalian glutathione synthesis. Free Radic. Biol. Med. 27, 922-935.

81) Tateishi, N., Higashi, T., Naruse, A., Nakashima, K. and Shiozaki, H. (1977) Rat liver glutathione: possible role as a reservoir of cysteine. J. Nutr. 107, 51-60.

82) Nagahara, N., Yoshii, T., Abe, Y. and Matsumura, T. (2007) Thioredoxin-dependent enzymatic activation of mercaptopyruvate sulfurtransferase. An intersubunit disulfide bond serves as a redox switch for activation. J. Biol. Chem. 282, 15611569 .

83) Westrop, G.D., Georg, I. and Coombs, G.H. (2009) The mercaptopyruvate sulfurtransferase of Trichomonas vaginalis links cysteine catabolism to the production of thioredoxin persulfide. J. Biol. Chem. 284, 33485-33494.

84) Holmgren, A. (2008) The thioredoxin system. In Redox Biochemistry (ed. Banerjee, R.). John Wiley \& Sons, Hoboken, NJ, pp. 68-74.

85) Spyrou, G., Enmark, E., Miranda-Vizuete, A. and Gustafsson, J.A. (1997) Cloning and expression of a novel mammalian thioredoxin. J. Biol. Chem. 272, 2936-2941.

86) Amer, E.S., Sarioglu, H., Lottspeich, F., Holmgren, A. and Bock, A. (1999) High-level expression in Escherichia coli of selenocysteine-containing rat thioredoxin reductase utilizing gene fusions with engineered bacterial-type SECIS elements and coexpression with the selA, SelB and SelC genes. J. Meol. Ciol. 292, 1003-1016.

87) Fujiwara, N., Fujii, T., Fujii, J. and Taniguchi, N. (1999) Functional expression of rat thioredoxin reductase: selenocysteine insertion sequence element is essential for the active enzyme. Biochem. J. 340, 439-444.

88) Kataoka, H., Hirabayashi, N. and Makita, M. (1993) Analysis of lipoic acid in biological samples by gas chromatography with flame photometric detection. J. Chromatogr. 615, 197-202.

89) Yadav, P.K., Yamada, K., Chiku, T., Koutmos, M. and Banerjee, R. (2013) Structure and kinetic analysis of $\mathrm{H}_{2} \mathrm{~S}$ production by human mercaptopyruvate sulfurtransferase. J. Biol. Chem. 288, 20002-20013.

90) Holmgren, A. (1986) Thioredoxin. 6. The amino acid sequence of the protein from Escherichia coli B. Eur. J. Biochem. 6, 475-484.

91) Jocelyn, P.C. (1967) The standard redox potential of cysteine-cystine from the thiol-disulphide exchange reaction with glutathione and lipoic acid. Eur. J. Biochem. 2, 327-331.

92) Cleland, W.W. (1964) Dithiothreitol, a new protective reagent for SH groups. Biochemistry 3, 480482 .
93) Burton, K. and Wilson, T.H. (1953) The free-energy changes for the reduction of diphosphopyridine nucleotide and the dehydrogenation of L-malate and L-glycerol 1-phosphate. Biochem. J. 54, 8694.

94) Wolosker, H., Sheth, K.N., Takahashi, M., Mothet, J.P., Brady, R.O. Jr., Ferris, C.D. and Snyder, S.H. (1999) Purification of serine racemase: biosynthesis of the neuromodulator D-serine. Proc. Natl. Acad. Sci. U.S.A. 96, 721-725.

95) Kim, P.M., Duan, X., Huang, A.S., Liu, C.Y., Ming, G.L., Song, H. and Snyder, S.H. (2010) Aspartate racemase, generating neuronal D-aspartate, regulates adult neurogenesis. Proc. Natl. Acad. Sci. U.S.A. 107, 3175-3179.

96) Riemenschneider, A., Wegele, R., Schmidt, A. and Papenbrock, J. (2005) Isolation and characterization of a D-cysteine desulfhydrase protein from Arabidopsis thaliana. FEBS J. 272, 1291-1304.

97) Huang, J., Niknahad, H., Khan, S. and O'Brien, P.J. (1998) Hepatocyte-catalysed detoxification of cyanide by L- and D-cysteine. Biochem. Pharmacol. 55, 1983-1990.

98) Schumann, U. and Subramani, S. (2008) Special delivery from mitochondria to peroxisomes. Trends Cell Biol. 18, 253-256.

99) Liardon, R. and Ledermann, S. (1986) Racemization kinetics of free and protein-bound amino acids under moderate alkaline treatment. J. Agric. Food Chem. 34, 557-565.

100) Friedman, M. (2010) Origin, microbiology, nutrition, and pharmacology of D-amino acids. Chem. Biodivers. 7, 1491-1530.

101) Krijgsheld, K.R., Glazenburg, E.J., Scholtens, E. and Mulder, G.J. (1981) The oxidation of L- and D-cysteine to inorganic sulfate and taurine in the rat. Biochim. Biophys. Acta 677, 7-12.

102) Bailey, T.S., Donor, M.T., Naughton, S.P. and Pluth, M.D. (2015) A simple bioluminescent method for measuring D-amino acid oxidase activity. Chem. Commun. (Camb.) 51, 54255428.

103) Kimura, Y. and Kimura, H. (2004) Hydrogen sulfide protects neurons from oxidative stress. FASEB J. 18, 1165-1167.

104) Kimura, Y., Dargusch, R., Schubert, D. and Kimura, H. (2006) Hydrogen sulfide protects HT22 neuronal cells from oxidative stress. Antioxid. Redox Signal. 8, 661-670.

105) Choi, D.W. (1988) Glutamate neurotoxicity and diseases of the nervous system. Neuron 1, 623634.

106) Murphy, T.H., Miyamoto, M., Sastre, A., Schnaar, R.L. and Coyle, J.T. (1989) Glutamate toxicity in a neuronal cell line involves inhibition of cystine transport leading to oxidative stress. Neuron 2, 1547-1558.

107) Kimura, Y., Goto, Y.-I. and Kimura, H. (2010) Hydrogen sulfide increases glutathione production and suppresses oxidative stress in mitochondria. Antioxid. Redox Signal. 12, 1-13.

108) Elrod, J.W., Calvert, J.W., Morrison, J., Doeller, 
J.E., Kraus, D.W., Tao, L., Jiao, X., Scalia, R., Kiss, L., Szabo, C., Kimura, H., Chow, C.-W. and Lefer, D.J. (2007) Hydrogen sulfide attenuates myocardial ischemia-reperfusion injury by preservation of mitochondrial function. Proc. Natl. Acad. Sci. U.S.A. 104, 15560-15565.

109) Tripatara, P., Patel, N.S.A., Collino, M., Gallicchio, M., Kieswich, J., Castiglia, S., Benetti, E., Stewart, K.N., Brown, P.A.J., Yaqoob, M.M., Fantozzi, R. and Thiemermann, C. (2008) Generation of endogenous hydrogen sulfide by cystathionine $\gamma$-lyase limits renal ischemia/reperfusion injury and dysfunction. Lab. Invest. 88, 1038-1048.

110) Zhu, J.X.G., Kalbfleisch, M., Yang, Y.X., Bihari, R., Lobb, I., Davison, M., Mok, A., Cepinskas, G., Lawendy, A.-R. and Sener, A. (2012) Detrimental effects of prolonged warm renal ischaemia-reperfusion injury are abrogated by supplemental hydrogen sulphide: an analysis using real-time intravital microscopy and polymerase chain reaction. Br. J. Urol. Int. 110, E1218-E1227.

111) Okamoto, M., Yamaoka, M., Takei, M., Ando, T., Taniguchi, S., Ishii, I., Tohya, K., Ishizaki, T., Niki, I. and Kimura, T. (2013) Endogenous hydrogen sulfide protects pancreatic beta-cells from a high-fat diet-induced glucotoxicity and prevents the development of type 2 diabetes. Biochem. Biophys. Res. Commun. 442, 227-233.

112) Mikami, Y., Shibuya, N., Kimura, Y., Nagahara, N., Yamada, M. and Kimura, H. (2011) Hydrogen sulfide protects the retina from light-induced degeneration by the modulation of $\mathrm{Ca}^{2+}$ influx. J. Biol. Chem. 286, 39379-39386.

113) Malhotra, J.D. and Kaufman, R.J. (2007) Endoplasmic reticulum stress and oxidative stress: a vicious cycle or a double-edged sword? Antioxid. Redox Signal. 9, 2277-2293.

114) Krishnan, N., Fu, C., Pappin, D.J. and Tonks, N.K. (2011) $\mathrm{H}_{2} \mathrm{~S}$-induced sulfhydration of the phosphatase PTP1B and its role in the endoplasmic reticulum stress response. Sci. Signal. 4, ra86.

115) Shatalin, K., Shatalina, E., Mironov, A. and Nudler, E. (2011) $\mathrm{H}_{2} \mathrm{~S}$ : A universal defense against antibiotics in bacteria. Science 334, 986-990.

116) Aizenman, E., Lipton, D.A. and Loring, R.H. (1989) Selective modulation of NMDA responses by reduction and oxidation. Neuron 2, 1257-1263.

117) Tsugane, M., Nagai, Y., Kimura, Y., Oka, J.-I. and Kimura, H. (2007) Differentiated astrocytes acquire sensitivity to hydrogen sulfide that is diminished by the transformation into reactive astrocytes. Antioxid. Redox Signal. 9, 257-269.

118) Nagai, Y., Tsugane, M., Oka, J.-I. and Kimura, H. (2006) Polysulfides induce calcium waves in rat hippocampal astrocytes. J. Pharmacol. Sci. 100, 200.

119) Oosumi, K., Tsugane, M., Ishigami, M., Nagai, Y., Iwai, T., Oka, J.-I. and Kimura, H. (2010) Polysulfide activates TRP channels and increases intracellular $\mathrm{Ca}^{2+}$ in astrocytes. Neurosci. Res. 685, e109-e222.
120) Kimura, Y., Mikami, Y., Osumi, K., Tsugane, M., Oka, J.-I. and Kimura, H. (2013) Polysulfides are possible $\mathrm{H}_{2} \mathrm{~S}$-derived signaling molecules in rat brain. FASEB J. 27, 2451-2457.

121) Searcy, D.G. and Lee, S.H. (1998) Sulfur reduction by human erythrocytes. J. Exp. Zool. 282, 310322 .

122) Streng, T., Axelsson, H.E., Hedlund, P., Andersson, D.A., Jordt, S.E., Bevan, S., Andersson, K.E., Hogestatt, E.D. and Zygmunt, P.M. (2008) Distribution and function of the hydrogen sulfide-sensitive TRPA1 ion channel in rat urinary bladder. Eur. Urol. 53, 391-399.

123) Ogawa, H., Takahashi, K., Miura, S., Imagawa, T., Saito, S., Tominaga, M. and Ohta, T. (2012) $\mathrm{H}_{2} \mathrm{~S}$ functions as a nociceptive messenger throughtransient receptor potential ankyrin 1 (TRPA1) activation. Neuroscience 218, 335-343.

124) Nagy, P. and Winterbourn, C.C. (2010) Rapid reaction of hydrogen sulfide with the neutrophil oxidant hypochlorous acid to generate polysulfides. Chem. Res. Toxicol. 23, 1541-1543.

125) Cahoy, J.D., Emery, B., Kaushal, A., Foo, L.C., Zamanian, J.L., Christopherson, K.S., Xing, Y., Lubischer, J.L., Krieg, P.A., Krupenko, S.A., Thompson, W.J. and Barres, B.A. (2008) A transcriptome database for astrocytes, neurons, and oligodendrocytes: a new resource for understanding brain development and function. J. Neurosci. 28, 264-278.

126) Xiang, Y., Yuan, Q., Vogt, N., Looger, L.L., Jan, L.Y. and Jan, Y.N. (2010) Light-avoidancemediating photoreceptors tile the Drosophila larval body wall. Nature 468, 921-926.

127) Shigetomi, E., Tong, X., Kwan, K.Y., Corey, D.P. and Khakh, B.S. (2012) TRPA1 channels regulate astrocyte resting calcium and inhibitory synapse efficacy through GAT-3. Nat. Neurosci. 15, 7080 .

128) Shigetomi, E., Jackson-Weaver, O., Huckstepp, R.T., O'Dell, T.J. and Khakh, B.S. (2013) TRPA1 channels are regulators of astrocyte basal calcium levels and long-term potentiation via constitutive D-serine release. J. Neurosci. 33, $10143-10153$.

129) Kato, A., Ogura, M. and Suda, M. (1966) Control mechanism in the rat liver enzyme system converting L-methionine to L-cystine. 3. Noncompetitive inhibition of cystathionine synthetase-serine dehydratase by elemental sulfur and competitive inhibition of cystathionine-homoserine dehydratase by L-cysteine and L-cystine. J. Biochem. 59, 40-48.

130) Branzoli, U. and Massey, V. (1974) Evidence for an active site persulfide residue in rabbit liver aldehyde oxidase. J. Biol. Chem. 249, 4346-4349.

131) Conner, J. and Russell, P.J. (1983) Elemental sulfur: a novel inhibitor of adenylate kinase. Biochem. Biophys. Res. Commun. 113, 348-352.

132) Vandiver, M.S., Paul, B.D., Xu, R., Karuppagounder, S., Rao, F., Snowman, A.M., Ko, H.S., Lee, Y.I., Dawson, V.L., Dawson, T.M., 
Sen, N. and Snyder, S.H. (2013) Sulfhydration mediates neuroprotective actions of parkin. Nat. Commun. 4, 1626.

133) Tao, B.B., Liu, S.Y., Zhang, C.C., Fu, W., Cai, W.J., Wang, Y., Shen, Q., Wang, M.J., Chen, Y., Zhang, L.J. and Zhu, Y.Z. (2013) VEGFR2 functions as an $\mathrm{H}_{2} \mathrm{~S}$-targeting receptor protein kinase with its novel Cys1045-Cys1024 disulfide bond serving as a specific molecular switch for hydrogen sulfide actions in vascular endothelial cells. Antioxid. Redox Signal. 19, 448-464.

134) Cai, W.J., Wang, M.J., Moore, P.K., Jin, H.M., Yao, T. and Zhu, Y.C. (2007) The novel proangiogenic effect of hydrogen sulfide is dependent on Akt phosphorylation. Cardiovasc. Res. 76, 29-40.

135) Papapetropoulos, A., Pyriochou, A., Altaany, Z., Yang, G., Marazioti, A., Zhou, Z., Jeschke, M.G., Branski, L.K., Herndon, D.N., Wang, R. and Szabo, C. (2009) Hydrogen sulfide is an endogenous stimulator of angiogenesis. Proc. Natl. Acad. Sci. U.S.A. 106, 21972-21977.

136) Calvert, J.W., Jha, S., Gundewar, S., Elrod, J.W., Ramachandran, A., Pattillo, C.B., Kevil, C.G. and Lefer, D.J. (2009) Hydrogen sulfide mediates cardioprotection through Nrf2 signaling. Circ. Res. 105, 365-374.

137) Yang, G., Zhao, K., Ju, Y., Mani, S., Cao, Q. Puukila, S., Khaper, N., Wu, L. and Wang, R. (2013) Hydrogen sulfide protects against cellular senescence via S-sulfhydration of Keap1 and activation of Nrf2. Antioxid. Redox Signal. 18, 1906-1919.

138) Koike, S., Ogasawara, Y., Shibuya, N., Kimura, H. and Ishii, K. (2013) Polysulfide exerts a protective effect against cytotoxicity caused by t-buthylhydroperoxide through Nrf2 signaling in neuroblastoma cells. FEBS Lett. 587, 3548-3555.

139) Massey, V., Williams, C.H. and Palmer, G. (1971) The presence of S0-containing impurities in commercial samples of oxidized glutathione and their catalytic effect in the reduction of cytochrome c. Biochem. Biophys. Res. Commun. 42, $730-738$.

140) Francoleon, N.E., Carrington, S.J. and Fukuto, J.M. (2011) The reaction of $\mathrm{H}_{2} \mathrm{~S}$ with oxidized thiols: Generation of persulfides and implications to $\mathrm{H}_{2} \mathrm{~S}$ biology. Arch. Biochem. Biophys. 516, $146-153$.

141) Ida, T., Sawa, T., Ihara, H., Tsuchiya, Y., Watanabe, Y., Kumagai, Y., Suematsu, M., Motohashi, H., Fujii, S., Matsunaga, T., Yamamoto, M., Ono, K., Davarie-Baez, N.O., Xian, M., Fukuto, J.M. and Akaike, T. (2014) Reactive cysteine persulfides and S-polythiolation regulate oxidative stress and redox signaling. Proc. Natl. Acad. Sci. U.S.A. 111, 7606-7611.

142) Brigham, M.P., Stein, W.H. and Moore, S. (1960) The concentrations of cysteine and cystine in human blood plasma. J. Clin. Invest. 39, 16331638.

143) Libiad, M., Yadav, P.K., Vitvitsky, V., Martinov,
M. and Banerjee, R. (2014) Organization of the human mitochondrial hydrogen sulfide oxidation pathway. J. Biol. Chem. 289, 30901-30910.

144) Ali, M.Y., Ping, C.Y., Mok, Y.-Y.P., Ling, L., Whiteman, M., Bhatia, M. and Moore, P.K. (2006) Regulation of vascular nitric oxide in vitro and in vivo; a new role for endogenous hydrogen sulphide? Br. J. Pharmacol. 149, 625-634.

145) Minamishima, S., Bougaki, M., Sips, P.Y., Yu, J.D., Minamishima, Y.A., Elrod, J.W., Lefer, D.J., Bloch, K.D. and Ichinose, F. (2009) Hydrogen sulfide improves survival after cardiac arrest and cardiopulmonary resuscitation via a nitric oxide synthase 3 -dependent mechanism in mice. Circulation 120, 888-896.

146) King, A.L., Polhemus, D., Bhushan, S., Otsuka, H., Kondo, K., Nicholson, C.K., Bradley, J.M., Islam, K.N., Calvert, J.W., Tao, Y.-X., Dugas, T.R., Kelley, E.E., Elrod, J.W., Huang, P.L., Wang, R. and Lefer, D.J. (2014) Hydrogen sulfide cytoprotective signaling is endothelial nitric oxide synthase-nitric oxide dependent. Proc. Natl. Acad. Sci. U.S.A. 111, 3182-3187.

147) Bir, S.C., Kolluru, G.K., McCarthy, P., Shen, X., Pardue, S., Pattillo, C.B. and Kevil, C.G. (2012) Hydrogen sulfide stimulates ischemic vascular remodeling through nitric oxide synthase and nitrite reduction activity regulating hypoxiainducible factor- $1 \alpha$ and vascular endothelial growth factor-dependent angiogenesis. J. Am. Heart Assoc. 1, e004093.

148) Coletta, C., Papapetropoulos, A., Erdelyi, K., Olah, G., Modis, K., Panopoulos, P., Asimakopoulou, A., Gero, D., Sharina, I., Martin, E. and Szabo, C. (2012) Hydrogen sulfide and nitric oxide are mutually dependent in the regulation of angiogenesis and endothelium-dependent vasorelaxation. Proc. Natl. Acad. Sci. U.S.A. 109, 91619166.

149) Whiteman, M., Li, L., Kostetski, I., Chu, S.H., Siau, J.L., Bhatia, M. and Moore, P.K. (2006) Evidence for the formation of a novel nitrosothiol from the gaseous mediators nitric oxide and hydrogen sulphide. Biochem. Biophys. Res. Commun. 343, 303-310.

150) Ondrias, K., Stasko, A., Cacanyiova, S., Sulova, Z., Krizanova, O., Kristek, F., Malekova, L., Knezl, V. and Breier, A. (2008) $\mathrm{H}_{2} \mathrm{~S}$ and HS-donor NaHS releases nitric oxide from nitrosothiols, metal nitrosyl complex, brain homogenate and murine L1210 leukaemia cells. Pflugers. Arch. Eur. J. Physiol. 457, 271-279.

151) Filipovic, M.R., Miljkovic, J.L., Nauser, T., Royzen, M., Klos, K., Shubina, T., Koppenol, W.H., Lippard, S.J. and Ivanovic-Burmazovic, I. (2012) Chemical characterization of the smallest S-nitrosothiol, HSNO; cellular cross-talk of $\mathrm{H}_{2} \mathrm{~S}$ and S-nitrosothiols. J. Am. Chem. Soc. 134, 1201612027.

152) Eberhardt, M., Dux, M., Namer, B., Miljkovic, J., Cordasic, N., Will, C., Kichko, T.I., Roche, J., Fischer, M., Suarez, S.A., Bikiel, D., Dorsch, K., 
Leffler, A., Babes, A., Lampert, A., Lennerz, J.K., Jacobi, J., Marti, M.A., Doctorovich, F., Hogestatt, E.D., Zygmunt, P.M., IvanovicBurmazovic, I., Messlinger, K., Reeh, Pl. and Filipovic, M.R. (2014) $\mathrm{H}_{2} \mathrm{~S}$ and $\mathrm{NO}$ cooperatively regulate vascular tone by activating a neuroendocrine HNO-TRPA1-CGRP signaling pathway. Nat. Commun. 5, 4381.

153) Cortese-Krott, M.M., Fernandez, B.O., Santos, J.L.T., Mergia, E., Grman, M., Nagy, P., Kelm, M., Butler, A. and Feelisch, M. (2014) Nitrosopersulfide $\left(\mathrm{SSNO}^{-}\right)$accounts for sustained $\mathrm{NO}$ bioactivity of S-nitrosothiols following reaction with sulfide. Redox Biol. 2, 234-244.

154) Altaany, Z., Ju, Y., Yang, G. and Wang, R. (2014) The coordination of S-sulfhydration, S-nitrosylation, and phosphorylation of endothelial nitric oxide synthase by hydrogen sulfide. Sci. Signal. 7 (342), ra87.

155) Sasakura, K., Hanaoka, K., Shibuya, N., Mikami, Y., Kimura, Y., Komatsu, T., Ueno, T., Terai, T., Kimura, H. and Nagano, T. (2011) Development of a highly selective fluorescence probe for hydrogen sulfide. J. Am. Chem. Soc. 133, 18003-18005.

156) Lippert, A.R., New, E.J. and Chang, C.J. (2011) Rebased fluorescent probes for selective imaging of hydrogen sulfide in living cells. J. Am. Chem. Soc. 133, 10078-10080.

157) Peng, H., Cheng, Y., Dai, C., King, A.L., Predmore, B.L., Lefer, D.J. and Wang, B. (2011) A fluorescent probe for fast and quantitative detection of hydrogen sulfide in blood. Angew. Chem. Int. Ed. 50, 9672-9675.

158) Liu, C., Pan, J., Li, S., Zhao, Y., Wu, L.Y., Berkman, C.E., Whorton, A.R. and Xian, M. (2011) Capture and visualization of hydrogen sulfide by a fluorescent probe. Angew. Chem. Int. Ed. 50, 10327-10329.

159) Qian, Y., Karpus, J., Klabil, O., Zhang, S.-Y., Zhu, H.-L., Banerjee, R., Zhao, J. and He, C. (2011) Selective fluorescent probes for live-cell monitoring of sulphide. Nat. Commun. 2, 495.

160) Chen, W., Liu, C., Peng, B., Zhao, Y., Pacheco, A. and Xian, M. (2013) New fluorescent probes for sulfane sulfurs and the application in bioimaging. Chem. Sci. 4, 2892-2896.

161) Yang, W., Yang, G., Jia, X., Wu, L. and Wang, R. (2005) Activation of $\mathrm{K}_{\text {ATP }}$ channels by $\mathrm{H}_{2} \mathrm{~S}$ in rat insulin-secreting cells and the underlying mechanisms. J. Physiol. 569, 519-531.

162) Kaneko, Y., Kimura, Y., Kimura, H. and Niki, I. (2006) L-cysteine inhibits insulin release from the pancreatic beta-cell: Possible involvement of metabolic production of hydrogen sulfide, a novel gasotransmitter. Diabetes 55, 1391-1397.
163) Zanardo, R.C.O., Brancaleone, V., Distrutti, E., Fiorucci, S., Cirino, G. and Wallace, J.L. (2006) Hydrogen sulphide is an endogenous modulator of leukocyte-mediated inflammation. FASEB J. 20, $2118-2120$

164) Chattopadhyay, M., Kodela, R., Nath, N., Dastagirzqada, Y.M., Velazquez-Martinez, C.A., Boring, D. and Kashfi, K. (2012) Hydrogen sulfide-reasing NSAIDs inhibit the growth of human cancer cells: A general property and evidence of a tissue type-independent effect. Biochem. Pharmacol. 83, 715-722.

165) Olson, K.R., Dombkowski, R.A., Russell, M.J., Doellman, M.M., Head, S.K., Whitfield, N.L. and Madden, J.A. (2006) Hydrogen sulfide as an oxygen sensor/transducer in vertebrate hypoxic vasoconstriction and hypoxic vasodilation. J. Exp. Biol. 209, 4011-4023.

166) Caliendo, G., Cirino, G., Santagada, V. and Wallace, J.L. (2010) Synthesis and biological effects of hydrogen sulfide $\left(\mathrm{H}_{2} \mathrm{~S}\right)$ : development of $\mathrm{H}_{2} \mathrm{~S}$-releasing drugs as pharmaceuticals. J. Med. Chem. 53, 6275-6286.

167) Lee, Z.W., Zhou, J., Chen, C.S., Zhao, Y., Tan, C.H., Li, L., Moore, P.K. and Deng, L.W. (2011) The slow-releasing hydrogen sulfide donor, GYY4137, exhibits novel anti-cancer effects in vitro and in vivo. PLoS One 6, e21077.

168) Kodela, R., Chattopadhyay, M. and Kashfi, K. (2013) Synthesis and biological activity of NOSHnaproxen (AVT-219) and NOSH-sulindac (AVT$18 \mathrm{~A})$ as potent anti-inflammatory agents with chemotherapeutic potential. Medchemcomm. 4, $1472-1481$

169) Szabo, C., Coletta, C., Chao, C., Modis, K., Szczesny, B., Papapetropoulos, A. and Hellmich, M.R. (2013) Tumor-derived hydrogen sulfide, produced by cystathionine $\beta$-synthase, stimulates bioenergetics, cell proliferation, and angiogenesis in colon cancer. Proc. Natl. Acad. Sci. U.S.A. 110, 12474-12479.

170) Peng, Y.J., Nanduri, J., Raghuraman, G., Souvannakitti, D., Gadalla, M.M., Kumar, G.K., Snyder, S.H. and Prabhakar, N.R. (2010) $\mathrm{H}_{2} \mathrm{~S}$ mediates $\mathrm{O}_{2}$ sensing in the carotid body. Proc. Natl. Acad. Sci. U.S.A. 107, 10719-10724.

171) Kwak, W.J., Kwon, G.S., Jin, I., Kuriyama, H. and Sohn, H.Y. (2003) Involvement of oxidative stress in the regulation of $\mathrm{H}_{2} \mathrm{~S}$ production during ultradian metabolic oscillation of Saccharomyces cerevisiae. FEMS Microbiol. Lett. 219, 99-104.

(Received Dec. 26, 2014; accepted Feb. 25, 2015) 


\section{Profile}

Dr. Hideo Kimura was born in Osaka in 1956. He graduated from the University of Tokyo in 1980 and received his Ph.D. degree in 1985. He served the National Defense Medical College (1980-1990) and studied neurotransmission in the cerebellum under Dr. Y. Sakai. Dr. Kimura received training in molecular biology at the Cancer Institute (1985-1987) under Dr. Y. Fujii-Kuriyama. Dr. Kimura received further training as a postdoctoral fellow (1988-1991) at the Salk Institute for Biological Studies, where he isolated and characterized a novel growth factor, schwannoma-derived growth factor, under Dr. D. Schubert. Dr. Kimura continued serving as a staff and senior staff scientist at the Salk Institute until 1999, where he discovered that hydrogen sulfide $\left(\mathrm{H}_{2} \mathrm{~S}\right)$ acts as a neuromodulator in the brain; this paper was published in 1996. Subsequently, in 1997, he

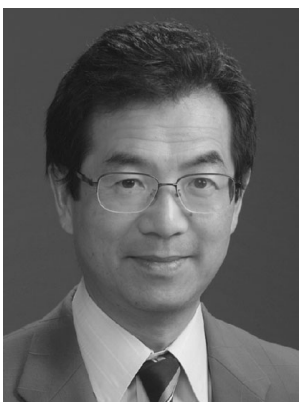
demonstrated another role for $\mathrm{H}_{2} \mathrm{~S}$, that is, it acts as a smooth muscle relaxant in synergy with nitric oxide. In 1999, he became Director of the Department of Molecular Genetics, National Institute of Neuroscience, National Center of Neurology and Psychiatry, Tokyo. Dr. Kimura discovered a neuroprotective effect of $\mathrm{H}_{2} \mathrm{~S}$ in 2004 that led to the identification of its protective effect against ischemic insults in various tissues and organs. In 2006, he also identified hydrogen polysulfide $\left(\mathrm{H}_{2} \mathrm{~S}_{\mathrm{n}}\right)$ as a potential signaling molecule which activates ion channels and was later found to have various other physiological roles, including the regulation of transcription factors, tumor-suppressing factors, and vascular tone. For his accomplishments, he received a Promotion Award from the Japanese Pharmacological Society, a Human Frontier Science Program Award, a First Award from the National Institutes of Health, an Alzheimer Scholar Award from the Alzheimer Association, and a JB Prize from the Japanese Biochemical Society. 